\title{
Rates and Mechanisms of Water Mass Transformation in the Labrador Sea as Inferred from Tracer Observations*
}

\author{
Samar Khatiwala, Peter Schlosser, and Martin Visbeck \\ Lamont-Doherty Earth Observatory and Department of Earth and Environmental Sciences, Columbia University, Palisades, New York
}

(Manuscript received 15 February 2000, in final form 8 May 2001)

\begin{abstract}
Time series of hydrographic and transient tracer $\left({ }^{3} \mathrm{H}\right.$ and $\left.{ }^{3} \mathrm{He}\right)$ observations from the central Labrador Sea collected between 1991 and 1996 are presented to document the complex changes in the tracer fields as a result of variations in convective activity during the 1990s. Between 1991 and 1993, as atmospheric forcing intensified, convection penetrated to progressively increasing depths, reaching $\sim 2300 \mathrm{~m}$ in the winter of 1993 . Over that period the potential temperature $(\theta)$ /salinity $(S)$ properties of Labrador Sea Water stayed nearly constant as surface cooling and downward mixing of freshwater was balanced by excavating and upward mixing of the warmer and saltier Northeast Atlantic Deep Water. It is shown that the net change in heat content of the water column (150-2500 m) between 1991 and 1993 was negligible compared to the estimated mean heat loss over that period $\left(110 \mathrm{~W} \mathrm{~m}^{-2}\right)$, implying that the lateral convergence of heat into the central Labrador Sea nearly balances the atmospheric cooling on a surprisingly short timescale. Interestingly, the ${ }^{3} \mathrm{H}-{ }^{3} \mathrm{He}$ age of Labrador Sea Water increased during this period of intensifying convection. Starting in 1995, winters were milder and convection was restricted to the upper $800 \mathrm{~m}$. Between 1994 and 1996, the evolution of ${ }^{3} \mathrm{H}-{ }^{3} \mathrm{He}$ age is similar to that of a stagnant water body. In contrast, the increase in $\theta$ and $S$ over that period implies exchange of tracers with the boundaries via both an eddy-induced overturning circulation and along-isopycnal stirring by eddies [with an exchange coefficient of $O\left(500 \mathrm{~m}^{2} \mathrm{~s}^{-1}\right)$ ].

The authors construct a freshwater budget for the Labrador Sea and quantitatively demonstrate that sea ice meltwater is the dominant cause of the large annual cycle of salinity in the Labrador Sea, both on the shelf and the interior. It is shown that the transport of freshwater by eddies into the central Labrador Sea $(\sim 140 \mathrm{~cm}$ between March and September) can readily account for the observed seasonal freshening. Finally, the authors discuss the role of the eddy-induced overturning circulation with regard to transport and dispersal of the newly ventilated Labrador Sea Water to the boundary current system and compare its strength (2-3 Sv) to the diagnosed buoyancy-forced formation rate of Labrador Sea Water.
\end{abstract}

\section{Introduction}

The Labrador Sea is the site of intense air-sea interaction, resulting in convection that in recent years has reached depths greater than $2000 \mathrm{~m}$ (Lab Sea Group 1998). In response to such wintertime convection, a weakly stratified water mass, Labrador Sea Water (LSW), of nearly uniform temperature and salinity has developed. Because of both its importance for the climate system and the fundamental fluid dynamics involved, the process of water mass transformation due to buoyancy-forced convection has attracted much attention. Over the past several years a series of observational campaigns has been conducted in the Labrador Sea to study various aspects of deep-water formation.

* Lamont-Doherty Earth Observatory Contribution Number 6172.

Corresponding author address: Dr. Samar Khatiwala, Department of Earth, Atmospheric and Planetary Sciences, Massachusetts Institute of Technology, Cambridge, MA 02139.

E-mail: spk@ocean.mit.edu
The Labrador Sea also provides an important setting in which to test parameterizations of subgrid-scale processes, a crucial aspect of large-scale numerical models.

In this study we present time series of temperature, salinity, tritium, and ${ }^{3} \mathrm{He}$ collected between 1991 and 1996 and relate them to the history of deep convection during that period. Whereas the interpretation of these time series is largely qualitative, they clearly indicate the importance of lateral exchange with the boundaries for the tracer balance of the central Labrador Sea (defined by the boxed region shown in Fig. 1) and demonstrate the utility of documenting the tracer "boundary conditions" for studies of deep water formation and spreading.

We also examine the annual cycle of salinity to quantify the importance of sea ice meltwater in producing the observed seasonal freshening in the central Labrador Sea. A persistent theme is the importance of eddies in the exchange of heat and salt between the boundaries and interior. Here, we provide additional evidence for a recently proposed eddy-induced "overturning" cir- 


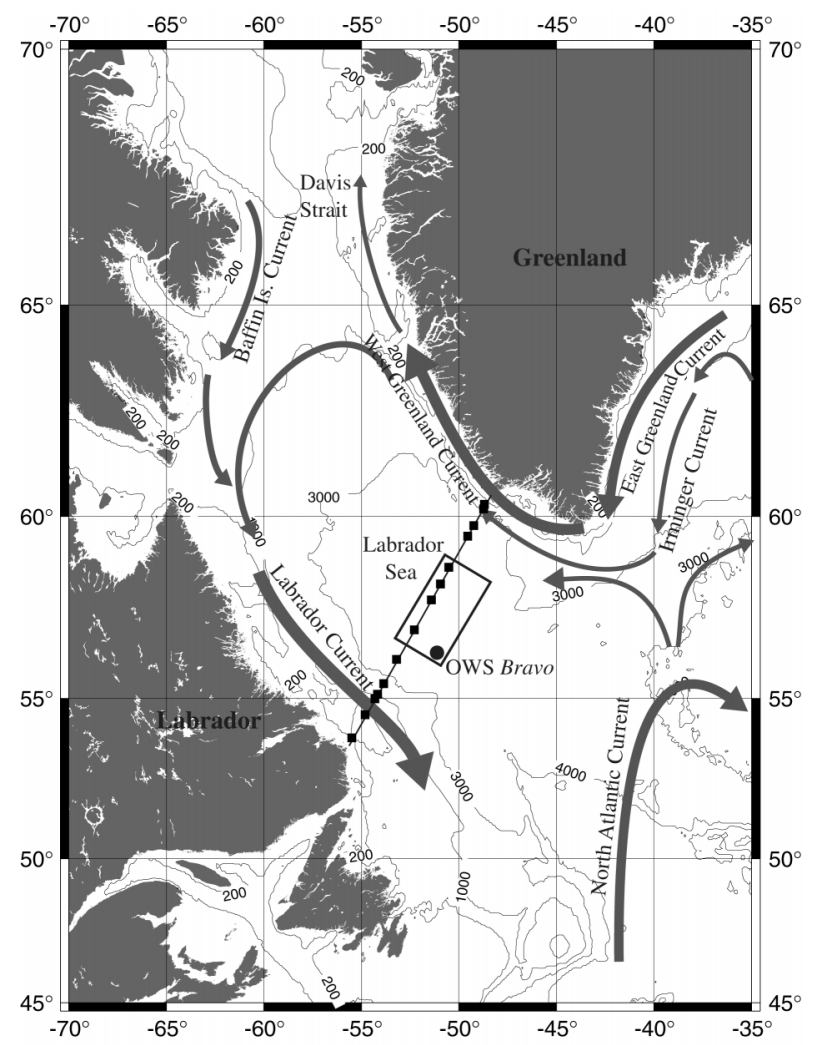

FIG. 1. Schematic of the circulation in the Labrador Sea. Major currents are indicated. Also shown is a typical WOCE AR7W cruise track and the nominal position of OWS Bravo. Solid squares show locations of stations occupied in Jun 1993 and at which samples for ${ }^{3} \mathrm{H}$ and ${ }^{3} \mathrm{He}$ were collected. Region used to define "central Labrador Sea" is marked by a rectangle.

culation and study its implications for freshwater transport into the central Labrador Sea as well as dispersal of newly ventilated LSW.

\section{Hydrography and circulation}

In this section we briefly review the circulation and hydrography of the Labrador Sea. The cyclonic circulation in the Labrador Sea (Fig. 1) is composed of three currents (Lazier 1973; Chapman and Beardsley 1989; Loder et al. 1998): the West Greenland Current, the Labrador Current, and the North Atlantic Current. Flowing northward along the continental shelf and slope off Greenland is the West Greenland Current, a continuation of the East Greenland Current, carrying cold, fresh polar water out of the Arctic Ocean. Although most of the West Greenland Current flows into Baffin Bay, a part of it turns westward just south of Davis Strait and joins the Baffin Island Current that flows south out of Baffin Bay. The Baffin Island Current then continues southward as the Labrador Current, transporting cold and fresh polar water over the upper continental slope and shelves of Labrador and Newfoundland (Lazier and Wright 1993; Loder et al. 1998; Khatiwala et al. 1999), as can be seen in hydrographic sections (Fig. 2) across the Labrador Sea (occupied in 1993). These low salinity shelf waters penetrate into the interior of the Labrador Sea, but are restricted to the upper 100-200 m. In contrast, the Irminger Current waters observed on the slope are warmer and saltier. The Irminger Current also flows cyclonically around the Labrador Sea on the West Greenland and Labrador slopes, and is distinguished by subsurface temperature $\left(>4^{\circ} \mathrm{C}\right)$ and salinity maxima $(>34.9 \mathrm{psu})$. The Irminger Current is an important source of heat and salt to the Labrador Sea, balancing both the annual mean surface heat loss $\left[\sim 50 \mathrm{~W} \mathrm{~m} \mathrm{~m}^{-2}\right.$ (Smith and Dobson 1984; Kalnay et al. 1996)] and the addition of freshwater from the boundary currents.

In the center of the cyclonic gyre between 500 and 2300 dbar lies Labrador Sea Water, a relatively cold (Fig. 2a) and fresh (Fig. 2b) water mass renewed convectively during winter (Lazier 1973; Talley and McCartney 1982; Clarke and Gascard 1983; Lab Sea Group 1998). The potential density $\left(\sigma_{\theta}\right)$ section displayed in Fig. 2c shows the weak stratification characterizing LSW: between 500 and $2300 \mathrm{dbar} \sigma_{\theta}$ varies by only $\sim 0.02 \mathrm{~kg} \mathrm{~m}^{-3}$. In recent years, intense atmospheric forcing has led to convection to depths greater than 2000 m (Lab Sea Group 1998; Lilly et al. 1999). Underlying LSW are the two other components of North Atlantic Deep Water (NADW). Northeast Atlantic Deep Water (NEADW), characterized by a salinity maximum at around $3000 \mathrm{dbar}$, is a mixture of Iceland-Scotland overflow water and ambient northeast Atlantic water (Swift 1984). NEADW flows into the western Atlantic through the Charlie Gibbs Fracture Zone. Below this water mass Denmark Strait overflow water (DSOW), a colder and by far the densest water mass in the region (Swift et al. 1980), is observed. DSOW originates in the convective gyre north of Iceland and flows into the Irminger Sea via Denmark Strait. This water mass structure is summarized in the $\theta-S$ diagram shown in Fig. 3.

\section{Samples and measurements}

The samples used in this study were collected on various cruises to the Labrador Sea between 1991 and 1996. In March 1991, samples for tritium $\left({ }^{3} \mathrm{H}\right)$ and ${ }^{3} \mathrm{He}$ were collected from a station $\left(55.2^{\circ} \mathrm{N}, 47.1^{\circ} \mathrm{W}\right)$ in the Labrador Sea (McKee et al. 1995). Tracer measurements were performed at the Woods Hole Oceanographic Institution Helium Isotope Laboratory. Between 1992 and 1996, a repeat hydrographic section (AR7W) was occupied, typically in June, between Labrador and Greenland as part of the World Ocean Circulation Experiment (WOCE). A typical cruise track is shown in Fig. 1. The solid squares indicate the typical sampling density for ${ }^{3} \mathrm{H}$ and ${ }^{3} \mathrm{He}$ data. Samples for $\mathrm{He}$ isotope and tritium analysis were collected in 40-ml copper tubes sealed by stainless steel pinch-off clamps. Tritium samples were degassed using a high vacuum extraction system and stored in special glass bulbs with low He permeability 

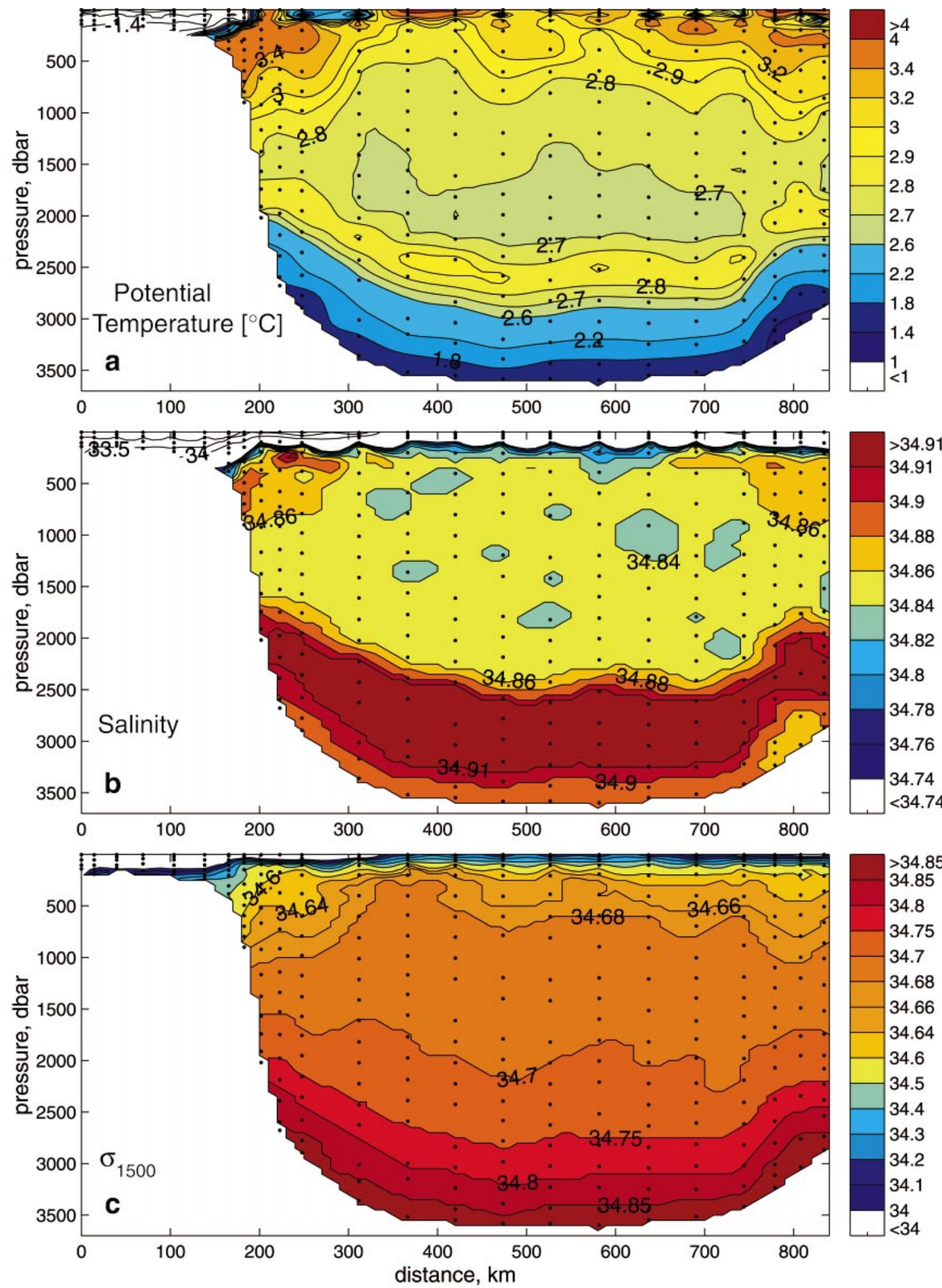

FIG. 2. Sections of (a) potential temperature, (b) salinity, and (c) $\sigma_{1500}$ across the Labrador Sea along the AR7W section occupied in Jun 1993 


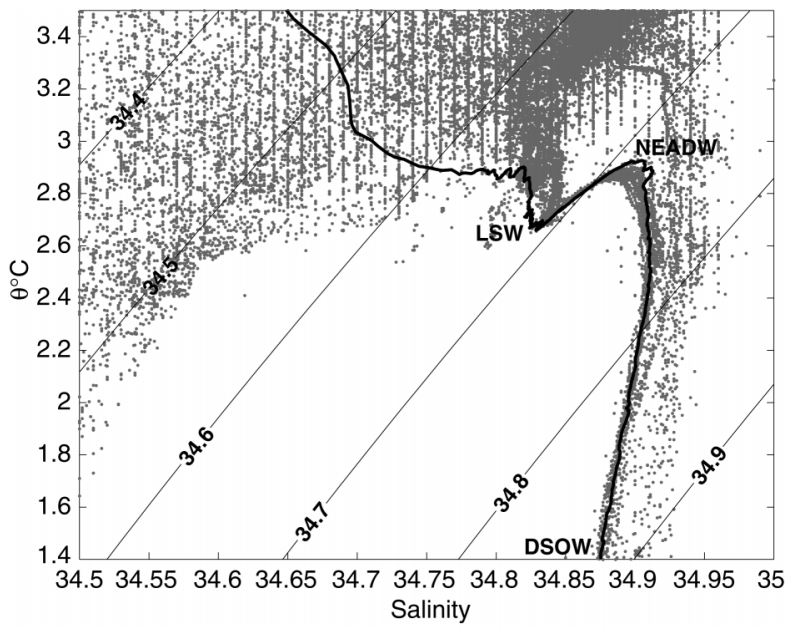

FIG. 3. $\theta-S$ plot for stations from the central Labrador Sea showing the water mass structure described in the text. The three main water masses, LSW, NEADW, and DSOW are indicated. The solid line is a CTD cast from spring $1994\left(58.2^{\circ} \mathrm{N}, 50.9^{\circ} \mathrm{W}\right)$. The gray dots representing all available data from the central Labrador Sea (see Fig. 1 for locations) show the extent of hydrographic variability. Note that the data coverage is biased toward the 1964-74 period. Also shown are contours of $\sigma_{1500}$.

for ingrowth of tritiogenic ${ }^{3} \mathrm{He}$. The ${ }^{3} \mathrm{He}$ ingrowth from tritium decay was measured on a commercial VG 5400 mass spectrometer with a specially designed inlet system (Ludin et al. 1998). Helium isotope samples were extracted using the same extraction system and measured on a similar mass spectrometric system (MM 5400). Precision of the tritium data reported here is $\pm 2 \%$, or $\pm 0.02 \mathrm{TU}$ (tritium units), while that of the ${ }^{3} \mathrm{He}$ data is $\pm 0.05 \mathrm{TU}$ (Ludin et al. 1998). The ${ }^{3} \mathrm{H}-{ }^{3} \mathrm{He}$ age in years was calculated by

$$
\tau_{t h}=\tau_{m} \ln \left(1+\frac{\left[{ }^{3} \mathrm{He}\right]}{\left[{ }^{3} \mathrm{H}\right]}\right)
$$

where $\tau_{m}$ is the mean lifetime of tritium (17.93 $\mathrm{yr}$ ).

\section{Overview of transient tracers}

In this section we present a brief overview of the transient tracers ${ }^{3} \mathrm{H}$ and ${ }^{3} \mathrm{He}$. Tritium is produced naturally in the upper atmosphere, where it is oxidized to HTO to participate in the hydrological cycle. Natural tritium concentrations in continental precipitation are $\sim 5$ TU [Roether (1967): 1 TU represents a ${ }^{3} \mathrm{H} / \mathrm{H}$ ratio of $10^{-18}$, while those in surface ocean water are $\approx 0.2$ TU (Dreisigacker and Roether 1978). This background signal was masked by anthropogenic tritium produced during atmospheric nuclear weapons tests, mainly in the early 1960 s, and injected into the stratosphere. This elevated tritium concentrations in continental precipitation by two to three orders of magnitude, while those in Northern Hemisphere ocean surface waters increased to about 17 TU (Dreisigacker and Roether 1978). Pres- ently, the main source of tritium to the Labrador Sea is via the boundary currents transporting low-salinity water from the Arctic Ocean (Doney et al. 1993).

Tritium decays to ${ }^{3} \mathrm{He}$ with a half-life of 12.43 years (Unterweger et al. 1980), thus elevating the ${ }^{3} \mathrm{He} /{ }^{4} \mathrm{He}$ ratio in subsurface ocean waters above solubility equilibrium. In practice, a more useful quantity is tritiogenic ${ }^{3} \mathrm{He}$, which is derived from the measured ${ }^{3} \mathrm{He}$ concentration by correcting the latter for ${ }^{3} \mathrm{He}$ in solubility equilibrium and for ${ }^{3} \mathrm{He}$ originating from "excess" air (bubbles). In this study, tritiogenic ${ }^{3} \mathrm{He}$ will be reported in TU. ${ }^{3} \mathrm{He}$ is a gas and its concentration in a water parcel tends to shift toward solubility equilibrium with the atmosphere near the ocean surface; that is, the tritiogenic ${ }^{3} \mathrm{He}$ shifts toward 0 TU. By simultaneously measuring tritium and ${ }^{3} \mathrm{He}$ we can compute the apparent "age" of a water parcel (e.g., Jenkins and Clarke 1976). In the absence of mixing, this age is the time elapsed since the water parcel was isolated from the surface (e.g., by convection). Such ${ }^{3} \mathrm{H}-{ }^{3} \mathrm{He}$ ages $\left(\tau_{t h}\right)$ provide a first-order estimate of renewal rates and residence times. It should be emphasized that the ${ }^{3} \mathrm{He}$ concentration in the mixed layer is rarely in solubility equilibrium. Indeed, in regions with deep mixed layers (Fuchs et al. 1987) and rapid convection the finite gas exchange velocity (5-10 $\mathrm{m} \mathrm{day}^{-1}$ ) can prevent $\tau_{t h}$ from being reset to zero. Furthermore, exchange with the boundaries, and in particular with older recirculating waters, can also modify ${ }^{3} \mathrm{H}-{ }^{3} \mathrm{He}$ ages in a manner that complicates straightforward interpretation.

\section{Distribution of transient tracers in the Labrador Sea}

\section{a. ${ }^{3} \mathrm{H}$ and ${ }^{3} \mathrm{He}$}

Figure 4a shows the distribution of tritium across the Labrador Sea. The surface-intensified boundary currents with high tritium concentrations (4-7 TU) are clearly visible. This tritium is mixed laterally into the interior and then to depth during deep convection, thus producing the elevated tritium values of Labrador Sea Water.

The distribution of ${ }^{3} \mathrm{He}$ (Fig. 4b) mirrors that of ${ }^{3} \mathrm{H}$ and clearly shows recently ventilated LSW, marked by low excess ${ }^{3} \mathrm{He}$ concentrations. The NEADW underlying LSW is characterized by high $\left[{ }^{3} \mathrm{He}\right]$ and low $\left[{ }^{3} \mathrm{H}\right]$ values due to the long transit time from the eastern Atlantic. In contrast, DSOW, seen in the eastern part of the section on the west Greenland slope, has relatively low ${ }^{3} \mathrm{He}$ and high ${ }^{3} \mathrm{H}$ concentrations. Also interesting is the relatively high ${ }^{3} \mathrm{He}$ values found on the Labrador shelf. Such elevated ${ }^{3} \mathrm{He}$ concentrations are characteristic of Arctic waters, and are due to the large tritium values coupled with the strong stratification, which inhibits vertical mixing and gas exchange, thus building up excess ${ }^{3} \mathrm{He}$ (e.g., Schlosser et al. 1990). In the context of the Labrador shelf, the ${ }^{3} \mathrm{He}$ is likely transported from 

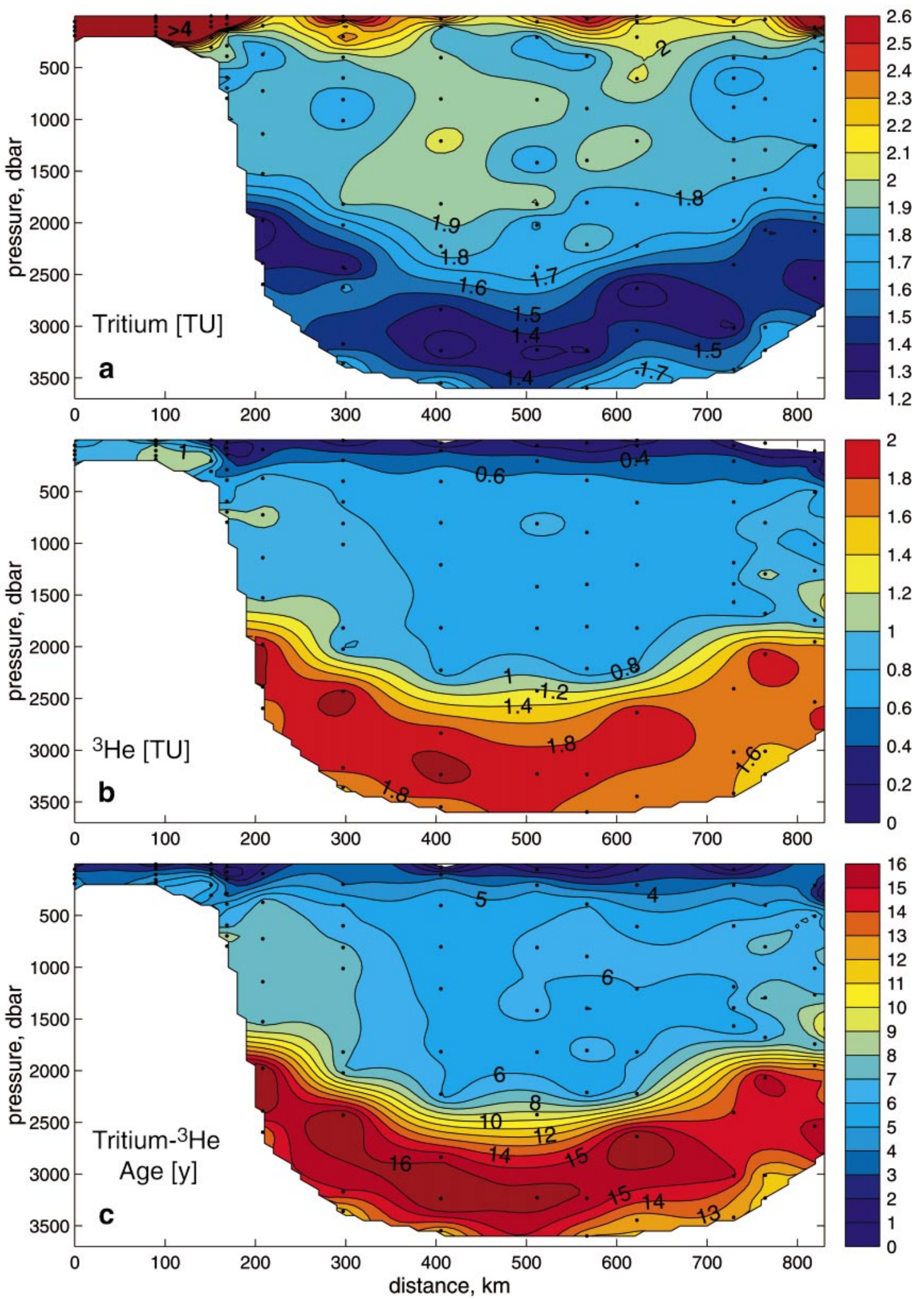

FIG. 4. Sections of (a) ${ }^{3} \mathrm{H}$, (b) ${ }^{3} \mathrm{He}$, and (c) ${ }^{3} \mathrm{H}-{ }^{3} \mathrm{He}$ age across the Labrador Sea along the WOCE AR7W section occupied in Jun 1993. 


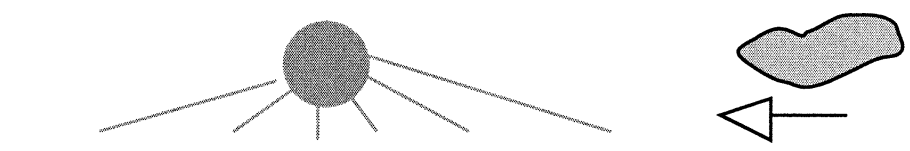

Atmospheric Mixed-Layer model

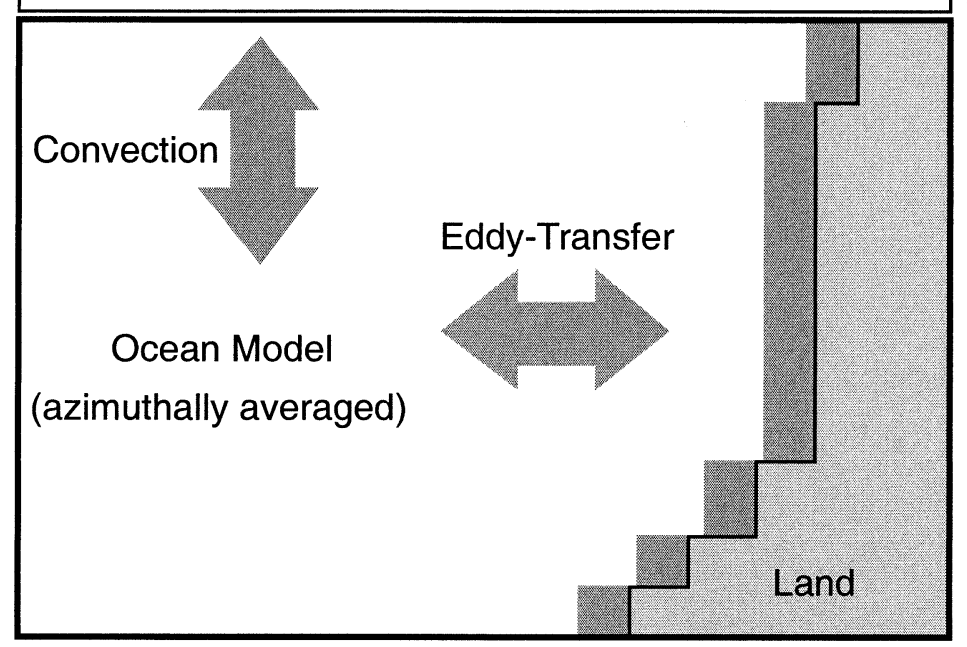

Specify land Temperature and Humidity (monthly)

Relax to "climatological" Temperature and Salinity
Restoring boundary conditions

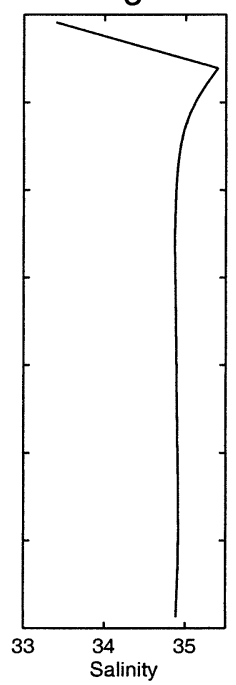

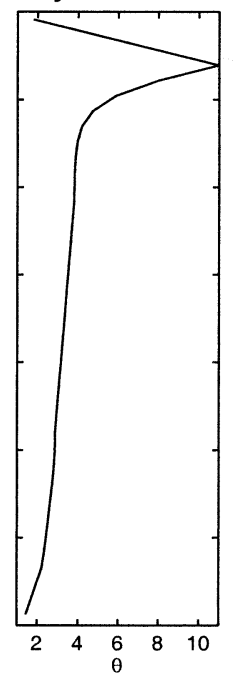

FIG. 5. A schematic of the 2D numerical model (horizontal resolution $40 \mathrm{~km}$, vertical resolution $87 \mathrm{~m}$, time step $4320 \mathrm{~s}$ ) showing its various components. Also shown are the $S$ and $\theta$ profiles to which the lateral boundary is relaxed.

farther north. For example, Top et al. (1981) have noted high subsurface ${ }^{3} \mathrm{He}$ concentrations in Baffin Bay, and it is possible that the ${ }^{3} \mathrm{He}$ observed on the Labrador shelf was transported in the Labrador Current from Baffin Bay.

\section{b. $3 \mathrm{H}-3 \mathrm{He}$ age}

Figure 4c shows the distribution of ${ }^{3} \mathrm{H}-{ }^{3} \mathrm{He}$ age $\left(\tau_{t h}\right)$. Not surprisingly, LSW shows the lowest $\tau_{t h}$ (4-6 yr), consistent with its recent ventilation. The next oldest water mass in the Labrador Sea is DSOW (12-14 yr), followed by NEADW (16 yr).

It should be emphasized that $\tau_{t h}$ is a rather crude measure of "age" and caution must be exercised in its interpretation. Indeed, in the presence of mixing a water parcel cannot be assigned a single age but must instead be characterized by an age distribution or distribution of transit times (Holzer and Hall 2000). However, as shown by Khatiwala et al. (2001), tracer-derived ages (such as $\tau_{t h}$ ) are weighted toward the leading part of the transit-time distribution and can accordingly be fruitfully interpreted and used. To better understand the behavior of transient tracers in a highly variable environment with relatively short timescales, such as the Labrador Sea, we have performed a series of simulations in a simple numerical model using idealized tracer boundary conditions. The model used here is two-dimensional, formulated in cylindrical coordinates, and based on the model described in Visbeck et al. (1997). A schematic of the model is shown in Fig. 5. Since, to first order, the distribution of various properties is symmetric about the central Labrador Sea, the Labrador Sea can be modeled as an azimuthally symmetric cylinder. In the context of the numerical model, the domain is thus a radial section across this cylinder.

The model solves the linearized momentum equations in the hydrostatic, geostrophic, and Boussinesq limits. The ocean model is forced by surface fluxes of buoyancy. The surface heat fluxes are determined by a prognostic atmospheric boundary layer model (Seager et al. $1995)$ coupled to the ocean model's sea surface temperature. The boundary layer atmospheric temperature and humidity are specified over land but vary over the ocean according to an advective-diffusive balance subject to air-sea fluxes. All other boundary conditions such as the shortwave radiation, cloud cover, wind speed, and wind vector are specified at each grid point with monthly resolution. The prescribed monthly mean air temperature and humidity are based on monthly mean meteorological data (collected between 1935 and 1995) from weather stations (Cartwright and Hopedale) 
on the Labrador coast. The predominantly northwesterly (cyclonic) winds justify the use of data from the Labrador coast rather than from the West Greenland coast. Monthly mean values for other variables were derived from da Silva et al. (1994).

Tracers in the model are restored to prescribed values at the lateral boundaries (Fig. 5). This is necessary because the ocean model has solid boundaries, and surface fluxes of tracers (e.g., heat and freshwater) must be balanced by sources or sinks elsewhere. In the Labrador Sea, surface heat loss and freshwater input are balanced by the convergence of heat and salt mixed in from the warmer and saltier boundary currents. In the model, this interaction with the large-scale circulation is represented by means of relaxation boundary conditions at the periphery. These restoring boundary conditions (Fig. 5) and the relaxation timescale ( $\sim 4$ months) were derived by minimizing the weighted sum of the square of the differences between model and observed variables [for details see Khatiwala (2000)]. The model removes instabilities created by surface forcing by a simple convective adjustment scheme that mixes adjacent cells in the vertical until the water column is stable. Transport of tracers by eddies is parameterized by the GentMcWilliams scheme (Gent and McWilliams 1990; Visbeck et al. 1997) using an exchange coefficient, $\kappa$, of $400 \mathrm{~m}^{2} \mathrm{~s}^{-1}$. Exchange of ${ }^{3} \mathrm{He}$ between the ocean mixed layer and atmosphere is parameterized in terms of a gas exchange velocity. The gas exchange velocity for ${ }^{3} \mathrm{He}$ $\left(v_{h e}\right)$ in $\mathrm{cm} \mathrm{h}^{-1}$ is computed following Wanninkhof (1992):

$$
v_{h e}=\frac{0.39 w^{2}}{\sqrt{\mathrm{Sc} / 660}},
$$

where $w$ is the surface wind speed and $\operatorname{Sc}(T)$ is the Schmidt number for ${ }^{3} \mathrm{He}$ at temperature $T$ (in ${ }^{\circ} \mathrm{C}$ ) calculated as

$\mathrm{Sc}=410.14-20.503 T+0.53175 T^{2}-0.0060111 T^{3}$.

The flux of tritiogenic ${ }^{3} \mathrm{He}$ out of the ocean is then given by $v_{h e}\left[{ }^{3} \mathrm{He}\right] / \Delta z$ where ${ }^{3} \mathrm{He}$ is the surface concentration and $\Delta z$ is the thickness of the surface grid box.

In each of the simulations discussed here, the model was "spun up" for 30 years before initializing any passive tracers. Thereafter, the model was integrated for an additional 70 years. Only the last two years of the simulation will be shown. The maximum depth of convection was $2300 \mathrm{~m}$. In the first experiment ${ }^{3} \mathrm{H}$ was strongly relaxed at the surface to $1 \mathrm{TU}$ with a timescale of 0.2 days, while ${ }^{3} \mathrm{He}$ was allowed to approach solubility equilibrium via gas exchange. The model produced typical winter gas exchange rates of $10-12 \mathrm{~m}^{-1 a y}{ }^{-1}$. Both ${ }^{3} \mathrm{H}$ and ${ }^{3} \mathrm{He}$ were subject to no-flux boundary conditions at the lateral wall. The modeled $\theta$ and $S$ variations in the convecting "interior" are shown in the top two panels of Fig. 6 at 300, 500, and $1500 \mathrm{~m}$. There is a fairly robust seasonal cycle in $\theta$, which is also seen in the observations (Lazier 1980; Lilly et al. 1999). Winter
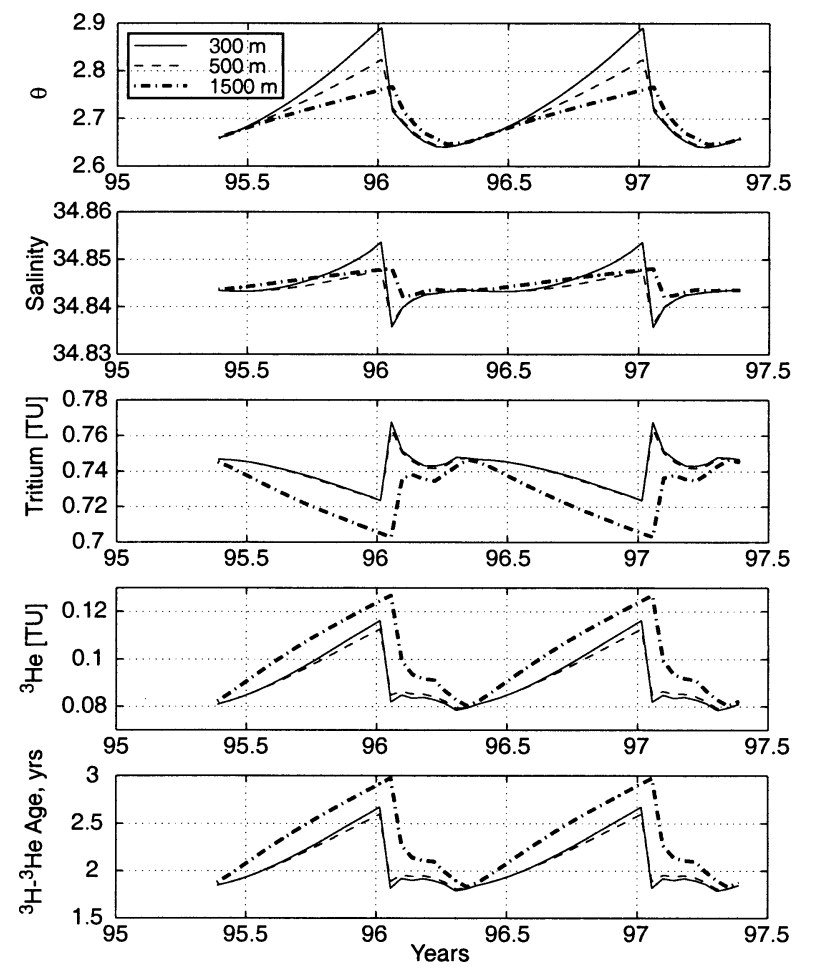

FIG. 6. Time series (from top to bottom) of $\theta, S,{ }^{3} \mathrm{H},{ }^{3} \mathrm{He}$, and $\tau_{t h}$ simulated in a numerical model at three different depths $(300,500$, and $1500 \mathrm{~m}$ ). No flux boundary conditions were imposed on ${ }^{3} \mathrm{H}$ and ${ }^{3} \mathrm{He}$ at the sidewall.

convection cools and freshens subsurface waters. Subsequently, $\theta$ and $S$ increase due to exchange with the warmer and saltier boundary waters. The simulated concentrations of ${ }^{3} \mathrm{H},{ }^{3} \mathrm{He}$, and calculated $\tau_{t h}$ are shown in the bottom three panels of Fig. 6 at 300, 500, and 1500 $\mathrm{m}$. Both ${ }^{3} \mathrm{H}$ and ${ }^{3} \mathrm{He}$ (and the calculated $\tau_{t h}$ ) undergo a strong seasonal cycle as a result of the winter deepening and subsequent shoaling of the mixed layer. It is suspected that this strong seasonality is in part due to the crude nature of the convective adjustment scheme employed, although no observations exist to demonstrate this. During winter, subsurface ${ }^{3} \mathrm{H}$ concentrations are elevated, while ${ }^{3} \mathrm{He}$ is lost to the atmosphere. Consequently, the ${ }^{3} \mathrm{H}-{ }^{3} \mathrm{He}$ age at $1500 \mathrm{~m}$ decreases from $3 \mathrm{yr}$ to $<2$ yr. Following wintertime convection, the ${ }^{3} \mathrm{H}-{ }^{3} \mathrm{He}$ age starts increasing. The modeled mean ${ }^{3} \mathrm{H}-{ }^{3} \mathrm{He}$ age at $1500 \mathrm{~m}$ is $\sim 2.5 \mathrm{yr}$, considerably less than the observed (in June) age of 4-6 yr.

While a detailed comparison between model and observations is obviously not very meaningful, we believe this difference in age is significant. One possibility is that lateral exchange with the relatively old waters along the boundaries of the Labrador Sea could affect the ${ }^{3} \mathrm{H}$ and ${ }^{3} \mathrm{He}$ concentrations, resulting in higher observed ages. To examine the influence of lateral mixing on ${ }^{3} \mathrm{H}-$ ${ }^{3} \mathrm{He}$ age a second experiment was performed with more realistic lateral boundary conditions imposed on ${ }^{3} \mathrm{H}$ and ${ }^{3} \mathrm{He}$. At the surface, ${ }^{3} \mathrm{H}$ was restored to observed values, 

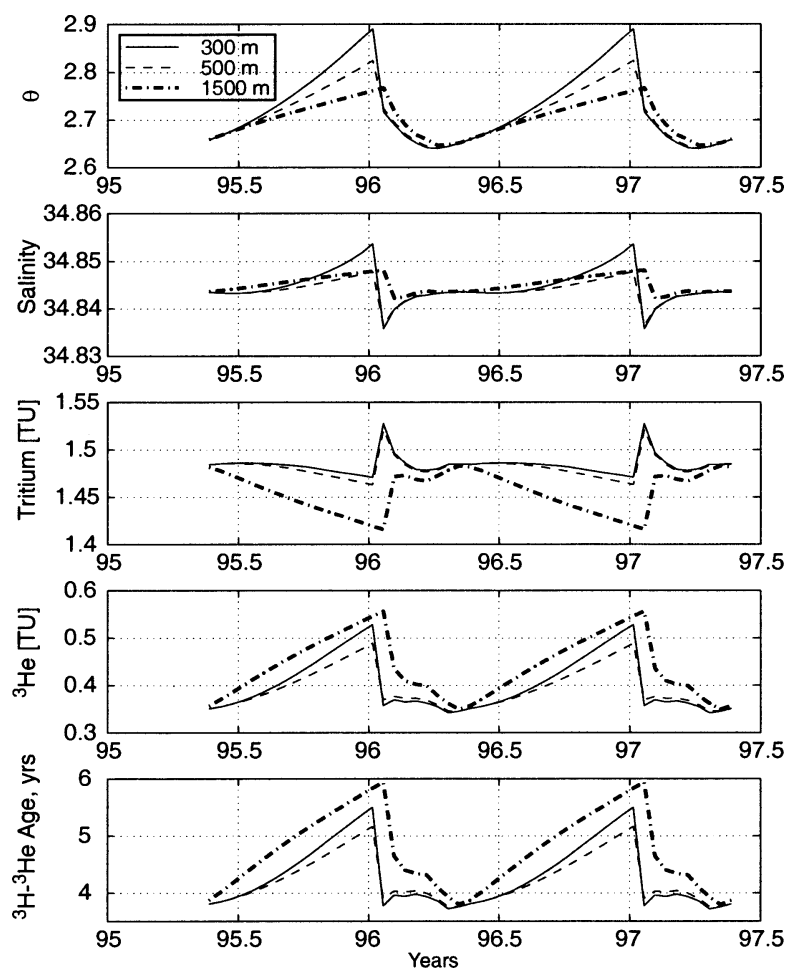

FIG. 7. Time series (from top to bottom) of $\theta, S,{ }^{3} \mathrm{H},{ }^{3} \mathrm{He}$, and $\tau_{t h}$ simulated in a numerical model at three different depths $(300,500$, and $1500 \mathrm{~m}) .{ }^{3} \mathrm{H}$ and ${ }^{3} \mathrm{He}$ were restored to observations at the sidewall.

while ${ }^{3} \mathrm{He}$ was subjected to gas exchange as before. More importantly, both ${ }^{3} \mathrm{H}$ and ${ }^{3} \mathrm{He}$ were restored to "observations" at the sidewall on a timescale of $\sim 4$ months. Just as for temperature and salinity these restoring conditions are a crude attempt to represent the boundary currents. The results of this experiment are shown in Fig. 7. The resulting ${ }^{3} \mathrm{H}-{ }^{3} \mathrm{He}$ age at $1500 \mathrm{~m}$ is now much greater. This suggests that the ${ }^{3} \mathrm{H}-{ }^{3} \mathrm{He}$ age is determined by a number of factors, such as intensity of convection, the extent to which the ${ }^{3} \mathrm{H}-{ }^{3} \mathrm{He}$ age is reset by gas exchange, and mixing with ambient waters with different tracer concentrations.

\section{Freshwater sources to the central Labrador Sea}

The nonlinear equation of state for seawater implies that salinity rather than temperature controls density (and hence stability) at the low temperatures characteristic of the subpolar ocean. As a result, changes in freshwater supply have the potential to impact deep convection. For example, the period of weak convection in the Labrador Sea during the late 1960s and early 1970s (Lazier 1995) has been linked to anomalously freshwaters in the subpolar North Atlantic (Dickson et al. 1988), and in particular on the West Greenland and Labrador shelves. It should be remembered that these low frequency fluctuations in the salinity of the near-surface Labrador Sea are in fact superposed on a large annual salinity cycle (Lazier 1980). In this section we examine this annual salinity signal. Previous work (e.g., Lazier 1982; Myers et al. 1990; Khatiwala et al. 1999) has focused on freshwater sources to the Labrador shelf and further downstream. Here we will synthesize the results of earlier studies in the context of understanding the freshwater inventory of the central Labrador Sea, and systematically construct a freshwater budget in terms of available sources. We begin by reviewing the freshwater balance on the shelves.

\section{a. Freshwater sources to the Labrador shelf}

Recent work by Loder et al. (1998) using hydrographic data and Khatiwala et al. (1999) using oxygen isotope $\left(\delta^{18} \mathrm{O}\right)$ measurements has examined the freshwater sources to the Labrador Sea. In particular, with the available $\delta^{18} \mathrm{O}$ data Khatiwala et al. (1999) concluded that high-latitude rivers dominated by Arctic runoff are the primary source of freshwater to the Labrador shelf. This freshwater is transported into the Labrador Sea via two pathways: the East-West Greenland Currents carrying low-salinity waters out of Fram Strait and the Baffin Island-Labrador Currents linking the Arctic Ocean to the Labrador Sea via the Canadian archipelago, Baffin Bay, and Davis Strait (Fig. 1). Consistent with hydrographic observations (Lazier and Wright 1993; Loder et al. 1998), the isotope data suggested that the latter pathway involving the Canadian archipelago predominates. The pervasive influence of sea ice on the Labrador shelf was also documented. The importance of Arctic runoff is also seen in tritium data (Khatiwala 2000).

\section{b. Annual cycle of salinity in the Labrador Sea}

As a first step, we have constructed a mean annual cycle of salinity in the central Labrador Sea using data collected between 1964 and 1974 at Ocean Weather Ship (OWS) Bravo $\left(56^{\circ} \mathrm{N}, 51^{\circ} \mathrm{W}\right)$, which was occupied in nearly all months during that period. We have not used data from other years because in most years only a few months were sampled at best. This poor coverage would be less of a problem but for the presence of long-term trends in the data (Lazier 1995), which could potentially influence the estimated annual cycle. Even during the 1964-74 period the observations show significant trends (Lazier 1980). In particular, the 1960s and early 1970s coincided with the passage of the Great Salinity Anomaly (Dickson et al. 1988), weak atmospheric forcing, and moderate convective activity. To remove these trends from the data a simple procedure was followed. A mean profile of salinity was constructed for each calender month between 1964 and 1974. Next, at each pressure level interpolation was performed in time to fill in the few missing months. A first-guess seasonal cycle was then estimated from the resulting gridded field. To detrend the data, the estimated annual cycle at 

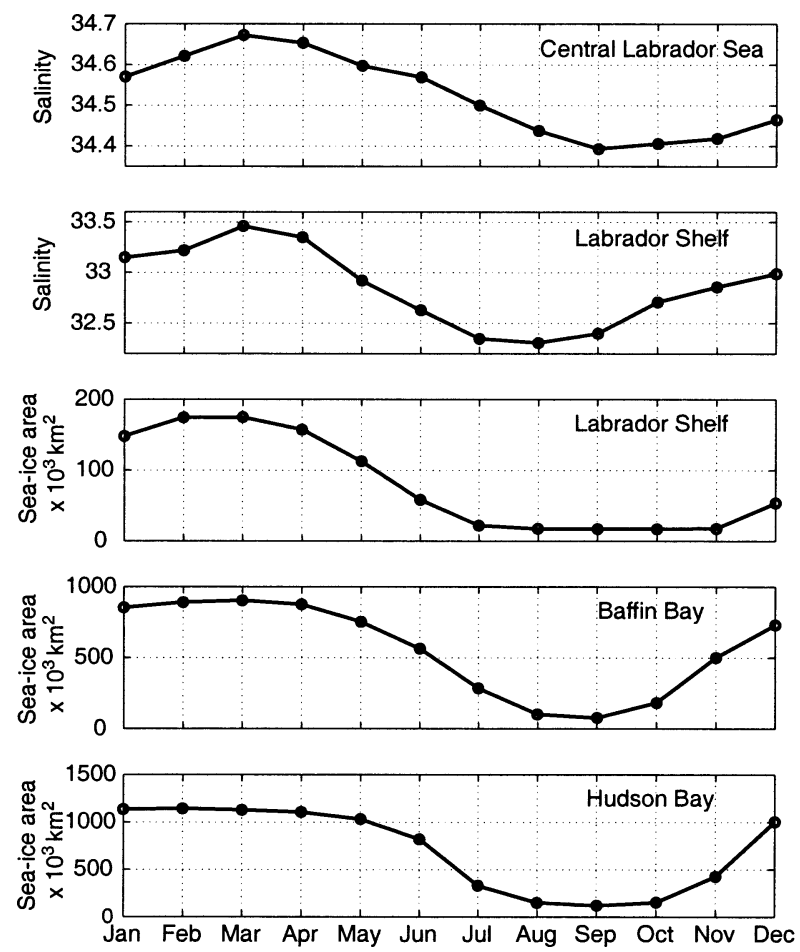

FIG. 8. Seasonal cycle (from top to bottom) of salinity in the central Labrador Sea (upper $100 \mathrm{~m}$ ) and on the Labrador shelf (upper 100 m) (Lazier 1982), and sea ice area on the Labrador Shelf, in Baffin Bay, and in Hudson Bay.

each pressure level was subtracted from the corresponding field and the residual smoothed with a 13-month boxcar filter to retain interannual variations. This smoothed residual was next subtracted from the original gridded field to obtain a detrended field. The procedure was repeated once more, but the results did not change significantly. The annual cycle we discuss below is derived from the detrended, gridded values.

The top panel in Fig. 8 shows the annual cycle of salinity in the central Labrador Sea averaged over the upper $100 \mathrm{~m}$. The salinity signal below a few hundred meters is weak and opposes the decrease in the upper $100 \mathrm{~m}$. Evidently, there is a large decrease in salinity between March and September, which corresponds to a change in salt content (over the upper $100 \mathrm{~m}$ ) of $\sim-20$ $\mathrm{kg} \mathrm{m}^{-2}$, or a salt outflux over that period of $1.3 \times 10^{-6}$ $\mathrm{kg} \mathrm{m}^{-2} \mathrm{~s}^{-1}$. Equivalently, assuming a mean surface salinity of $34.5 \mathrm{psu}$, this implies an addition of $60 \mathrm{~cm}$ of freshwater between March and September to the upper $100 \mathrm{~m}$, similar to the value calculated previously by Lazier (1980). Averaged over the upper 1500 m, however, the net change in salinity is negligible, approaching the measurement precision (Lazier, 1980).

As suggested by Lazier (1980), the salinity changes in the upper $100 \mathrm{~m}$ cannot be explained by precipitation ( $\sim 20 \mathrm{~cm}$ during summer). Instead, he attributed the seasonal salinity decrease to runoff and sea ice meltwater delivered into Hudson Bay (see below). This freshwater would be transported south in the Labrador Current and laterally mixed into the interior. Regardless of the source of the freshwater, in the absence of a mean advection into the interior of the Labrador Sea, eddy exchange appears to be the only plausible mechanism for the freshwater flux. An alternative is for sea ice to drift into the central Labrador Sea and then melt, but the available $\delta^{18} \mathrm{O}$ data suggest that this is not a significant mechanism (Khatiwala et al. 1999).

It should be noted that our estimate of the seasonal cycle is based on a period of low surface salinity in the Labrador Sea (Dickson et al. 1988; Lazier 1995) and weak convection. In years with more robust convection near-surface salinity in winter may well be higher. For example, in late February 1997 the salinity of the (well mixed) upper $100 \mathrm{~m}$ was typically $>34.8$ psu (Pickart et al. 2002). By mid-May of that year the salinity in the central Labrador Sea was $\sim 34.7$ psu. No data are available from later in the year to assess the amplitude of the seasonal cycle in recent years.

\section{c. Sources of freshwater}

An important question (Lab Sea Group 1998) is the contribution of sea ice melt to the seasonal freshening in the central Labrador Sea. The salinity data presented above do not directly identify the source of the freshwater, but the timing of the salinity minimum strongly hints at sea ice meltwater being the dominant source. To begin, consider the freshwater flux implied by the salinity data. To produce the March-September freshening in the central Labrador Sea requires $\sim 60 \mathrm{~cm}$ of freshwater, or a mean freshwater flux over that period of $11 \mathrm{mSv}\left(\mathrm{mSv} \equiv 10^{3} \mathrm{~m}^{3} \mathrm{~s}^{-1}\right)$. For this calculation we have used a disk of radius $300 \mathrm{~km}$ to represent the "central" Labrador Sea and assumed that the value of $60 \mathrm{~cm}$ derived mostly from observations at OWS Bravo is, in fact, representative of that area. Lazier (1980) obtains a value of $30 \mathrm{mSv}$ by using a substantially larger area, but it appears that his value was meant to apply to the entire Labrador Sea. In any event, this flux should be compared to the total freshwater transport of the Labrador and West Greenland Currents [ 200 and 30 $\mathrm{mSv}$ relative to $S=34.8 \mathrm{psu}$, respectively (Loder et al. 1998)] as well as that produced by melting of sea ice.

To estimate the freshwater contribution from melting of sea ice we have computed the annual cycle of sea ice area (Fig. 8) in Baffin Bay, Hudson Bay, and on the Labrador shelf from satellite microwave observations of sea ice concentration. By assuming an ice thickness of $2 \mathrm{~m}$ for Baffin Bay and Hudson Bay, and $1 \mathrm{~m}$ for the Labrador shelf (Ice Climatology Services 1992) the ice volumes were converted into a "discharge" rate. The peak (March-August average) discharge rates thus calculated are 19 (11) $\mathrm{mSv}$ for the Labrador shelf, 190 (110) $\mathrm{mSv}$ for Baffin Bay, and 335 (134) mSv for Hudson Bay. The maxima for sea ice melt in each of these regions occurs in June. In addition to meltwater, river 
TABLE 1. Freshwater volumes from various sources.

\begin{tabular}{lc}
\hline \hline \multicolumn{1}{c}{ Source } & $\begin{array}{c}\text { Volume } \\
\left(\times 10^{11} \mathrm{~m}^{3}\right)\end{array}$ \\
\hline Labrador shelf sea ice (Mar) & 1.6 \\
Baffin Bay and Davis Strait sea ice (Mar) & 16 \\
Hudson Bay sea ice (Mar) & 20 \\
Davis Strait ice drift (annual) & 11 \\
Labrador shelf ice drift (annual) & 3 \\
Davis Strait ice drift (Mar-Jun) & 5.6 \\
Labrador shelf ice drift (Mar-Jun) & 1.4 \\
Labrador shelf runoff (Mar-Sep) & 1 \\
Labrador shelf (top 200 m) required freshwater & 7 \\
Central Labrador Sea (top 100 m) required & 1.7 \\
$\quad$ freshwater & \\
\hline
\end{tabular}

runoff along the Labrador coast is about $5 \mathrm{mSv}$, while that into the Hudson Bay drainage area has a peak discharge rate (in June) of $\approx 60 \mathrm{mSv}$ (Inland Waters Directorate 1991). Undoubtedly, some of the sea ice existing at the beginning of the melt season is exported out of the region and will be lost as a freshwater source.

Consider now the timing of the salinity minimum in the Labrador Sea. The salinity minimum on the Labrador shelf occurs in July-August (Fig. 8) (Lazier 1982), while that in the central Labrador Sea occurs in September. The obvious explanation for this timing is the seasonal melting of sea ice in the region, but we also need to account for the export of sea ice out of the region. At this point it is more convenient to compare the volume of available freshwater sources. Since we are interested in the summer freshening we first calculate the amount of freshwater available in the form of sea ice at the beginning of the melt season. This is reported in Table 1 for the Labrador shelf $\left(1.6 \times 10^{11} \mathrm{~m}^{3}\right)$, Baffin Bay and Davis Strait $\left(16 \times 10^{11} \mathrm{~m}^{3}\right)$, and Hudson Bay $\left(20 \times 10^{11} \mathrm{~m}^{3}\right)$. Again, some of this ice, particularly on the Labrador shelf, will drift out of the region during the melt season and, while difficult to estimate just how much, an upper bound can be placed on the volumes involved. Ingram and Prinsenberg (1998) estimate the annual mean sea ice export through Davis Strait to be equivalent to $\sim 35 \mathrm{mSv}$ of freshwater, while Loder et al. (1998) estimate the sea ice drift along the southern Labrador coast (Hamilton Bank) to be $\sim 10 \mathrm{mSv}$. This represents an annual freshwater export of $11 \times 10^{11} \mathrm{~m}^{3}$ through Davis Strait and $3 \times 10^{11} \mathrm{~m}^{3}$ south of the Labrador shelf (Table 1). However, we are more interested in the ice export during summer. This can be crudely estimated as follows. The mean current velocity on the southern Labrador shelf is $\sim 10 \mathrm{~cm} \mathrm{~s}^{-1}$ (Lazier and Wright 1993), while that in Davis Strait is $\sim 20 \mathrm{~cm} \mathrm{~s}^{-1}$ (Ingram and Prinsenberg 1998). Assuming that the sea ice tracks the surface currents, for which there is some evidence, the potential export of ice between March and June is $\sim 5.6 \times 10^{11} \mathrm{~m}^{3}$ out of Davis Strait and $1.4 \times$ $10^{11} \mathrm{~m}^{3}$ across the southern Labrador shelf (assuming a width of $200 \mathrm{~km}$ for both sections). These should be considered upper bounds because according to satellite observations (Fig. 8) the ice cover is greatly reduced by June. Finally, runoff along the Labrador shelf contributes an additional $1 \times 10^{11} \mathrm{~m}^{3}$ between March and September.

Having looked at the sources, it is useful to compute the volume of freshwater required to produce the observed freshening in the Labrador Sea. For the central Labrador Sea we require $60 \mathrm{~cm}$ or $1.7 \times 10^{11} \mathrm{~m}^{3}$ of freshwater between March and September. On the Labrador shelf the mean salinity (upper $200 \mathrm{~m}$ ) changes by $\sim 0.75 \%$ between March and August (Lazier, 1982), requiring an addition of nearly $4.6 \mathrm{~m}$ of freshwater. Integrated over the entire shelf (width $\sim 150 \mathrm{~km}$ and length $\sim 1000 \mathrm{~km}$ ), this requires the addition of $7 \times$ $10^{11} \mathrm{~m}^{3}$ of freshwater between March and August. Over the entire Labrador Sea the seasonal freshening requires the addition of $\sim 9 \times 10^{11} \mathrm{~m}^{3}$ or $900 \mathrm{~km}^{3}$ of freshwater. All estimates are summarized in Table 1.

Clearly, although we have not included the contribution from runoff, Hudson Bay emerges as the largest potential source of freshwater. However, there is some debate as to the importance of Hudson Bay sea ice meltwater and runoff to the Labrador Sea. For example, Lazier (1980) suggests that the freshening in the Labrador Sea can be explained by Hudson Bay sources, while Lazier and Wright (1993) find evidence for the dominance of Baffin Bay. The latter view is also reflected in the freshwater estimates made by Loder et al. (1998). Furthermore, a lag-correlation analysis (Myers et al. 1990) shows that runoff into Hudson Bay has the most negative correlation with the salinity off Newfoundland (downstream of the Labrador shelf) at a lag of 9 months. Thus, the runoff pulse from Hudson Bay should reach the Newfoundland shelf in March. However, the salinity minimum off Newfoundland occurs in August-September, thus leading Myers et al. (1990) to conclude that Hudson Bay runoff does not contribute significantly to the salinity minimum off Labrador and Newfoundland. This inference is supported by data from a current meter in Hudson Strait where the surface salinity reaches its minimum in November. Significantly, they find no consistent evidence of any relationship between sea ice melt into Hudson Bay and salinity off Newfoundland. This is surprising considering that the freshwater discharge from sea ice melt is at least twice as large as that produced by runoff. They attribute this to the poor quality of sea ice data. In any event, the advective lags for both runoff and sea ice melt are likely to be similar and, along with the salinity observations from Hudson Strait, the evidence strongly suggests that neither river runoff nor sea ice melt from the Hudson Bay region contributes substantially to the seasonal freshening of the surface Labrador Sea. This leaves Baffin Bay as the primary source of freshwater, as there is insufficient sea ice on the Labrador shelf to provide the necessary $900 \mathrm{~km}^{3}$ of freshwater. It is supposed that over the summer months some fraction of the existing $16 \times 10^{11} \mathrm{~m}^{3}$ of sea ice from Baffin Bay and Davis 
Strait will be exported south and melt on the Labrador shelf, while some of it will melt in situ and be transported in the Baffin Island Current and onto the Labrador shelf. Lazier and Wright (1993) estimate that the seasonal freshening just south of Davis Strait is $\sim 70 \%$ of that on the Labrador shelf and suggest that this lowsalinity water is then advected south, producing the observed freshening on the Labrador shelf. This leaves us with $\sim 4 \times 10^{11} \mathrm{~m}^{3}$ of freshwater (split evenly between the Labrador shelf and the interior) unaccounted for, and from Table 1 we see that sea ice export through Davis Strait can reasonably explain the balance.

The estimates presented here, while rather crude, quantitatively support the idea that sea ice meltwater is the dominant cause of the large annual cycle in the Labrador Sea, both on the shelf and the interior. It is important to note that, since we are only discussing the seasonal cycle, this conclusion does not contradict the results of previous studies that identify Arctic runoff as the most important contributor to the average freshwater transport along the Labrador shelf. (Arctic runoff also spreads into the central Labrador Sea, as seen by high surface ${ }^{3} \mathrm{H}$ values.) Finally, it is interesting to note that the total sea ice exported south of the Labrador shelf is nearly twice that present at the end of winter on the Labrador shelf. This is consistent with the $\delta^{18} \mathrm{O}-S$ calculations of Khatiwala et al. (1999), which imply that nearly $2 \mathrm{~m}$ of sea ice is formed annually on the Labrador shelf as opposed to a directly observed value of $1 \mathrm{~m}$ (Ice Climatology Services 1992). That is, the total volume of ice produced on the Labrador shelf is nearly twice that present at the end of winter.

\section{Interannual variability in the Labrador Sea}

In this section we report changes in hydrographic and transient tracers in the central Labrador Sea between 1991 and 1996 and relate this variability to changes in the convective regime. It has long been recognized that the formation of Labrador Sea Water is not a steadystate process, but exhibits significant low frequency variability. Previous studies, notably those by Lazier (1980, 1995), have documented variability in the hydrographic properties of LSW on decadal timescales and related them to changes in convective activity. Here, we will focus on interannual changes in both hydrographic properties as well as transient tracers (tritium and ${ }^{3} \mathrm{He}$ ) and relate them to the history of convection in the 1990s.

The tracer data will be presented as time-pressure "sections", which were prepared as follows. Between 1991 and 1996, for every cruise, a mean profile of tracer in the central Labrador Sea (see Fig. 1 for locations) was constructed by linearly interpolating the data onto a uniform pressure grid. For $\theta, S$, and $\sigma_{1500}$, the higher resolution CTD data were used. Next, for each pressure level, the data were linearly interpolated onto a uniform time grid to arrive at the gridded (in time and pressure) tracer fields. For the purpose of inferring convection depths, we will also discuss the variation of tracer inventories in different layers (delineated by isobars).

\section{a. Potential temperature $(\theta)$ time series}

Figure 9a shows the evolution of $\theta$ in the central Labrador Sea between 1991 and 1996. Below 1000 dbar $\theta$ showed a monotonic decrease between 1991 and 1993 . (For reference, Fig. 9b shows the time evolution of $\sigma_{1500}$.) In particular, the mean $\theta$ between 1000 and 1500 dbar (core LSW) decreased by $\sim 0.1^{\circ} \mathrm{C}$ in that period. Interestingly, between 1991 and 1992, the average $\theta$ of the underlying layer (1500-2000 dbar) decreased by $\sim 0.15^{\circ} \mathrm{C}$ while that of the 500-1000-dbar layer remained virtually unchanged. This strongly suggests that the properties of LSW are determined in part by surface forcing and mixing with underlying waters. It is also clear that convection to successively deeper levels between 1991 and 1993 had eroded the upper part of NEADW (2000-2500 dbar) so that its temperature decreased by $\sim 0.3^{\circ} \mathrm{C}$. The mean temperature of the water column between 150 and 2500 dbar decreased by $\sim 0.1^{\circ} \mathrm{C}$. If the central Labrador Sea is treated as a onedimensional fluid column, then such a cooling would require a net heat loss of $15 \mathrm{~W} \mathrm{~m}^{-2}$ over the entire two year period. This number, however, should be compared with an estimated mean heat loss over that 2-yr period of $110 \mathrm{~W} \mathrm{~m}^{-2}$ (Kalnay et al. 1996). [We note that, according to Renfrew et al. (2002), National Centers for Environmental Prediction (NCEP) fluxes are somewhat biased toward higher values.] Comparing the actual cooling with that expected from a heat loss of $110 \mathrm{~W}$ $\mathrm{m}^{-2}$ (Fig. 10) implies that the convergence of heat into the central Labrador Sea nearly balances the atmospheric cooling. The relatively small net storage of heat points to an efficient mechanism for exchange between the boundaries and interior. Following the winter of 1994, the temperature increased at all depths, a feature discussed later.

It is also instructive to look at the time history of atmospheric forcing. In the absence of any wintertime measurements of heat loss during that period, we use the reanalyzed diagnostic net heat flux from the National Center for Atmospheric Research (NCAR)-NCEP data assimilation project (Kalnay et al. 1996). Measurements conducted during the Labrador Sea Deep Convection Experiment (Lab Sea Group 1998) in February and March of 1997 indicate that the diagnosed heat flux was somewhat higher than the measured values but did well in accounting for the heat storage inferred from CTD casts. It should be kept in mind that the shipboard measurements were not synoptic, which makes it difficult to directly test the accuracy of the diagnosed heat flux. The upper panel in Fig. 11 is a time series of winter [December-March (DJFM) mean] net heat loss in the central Labrador Sea. Also shown for reference is a time series of the winter (DJFM) index of the North Atlantic Oscillation (NAO) (Hurrell 1995) based on the differ- 

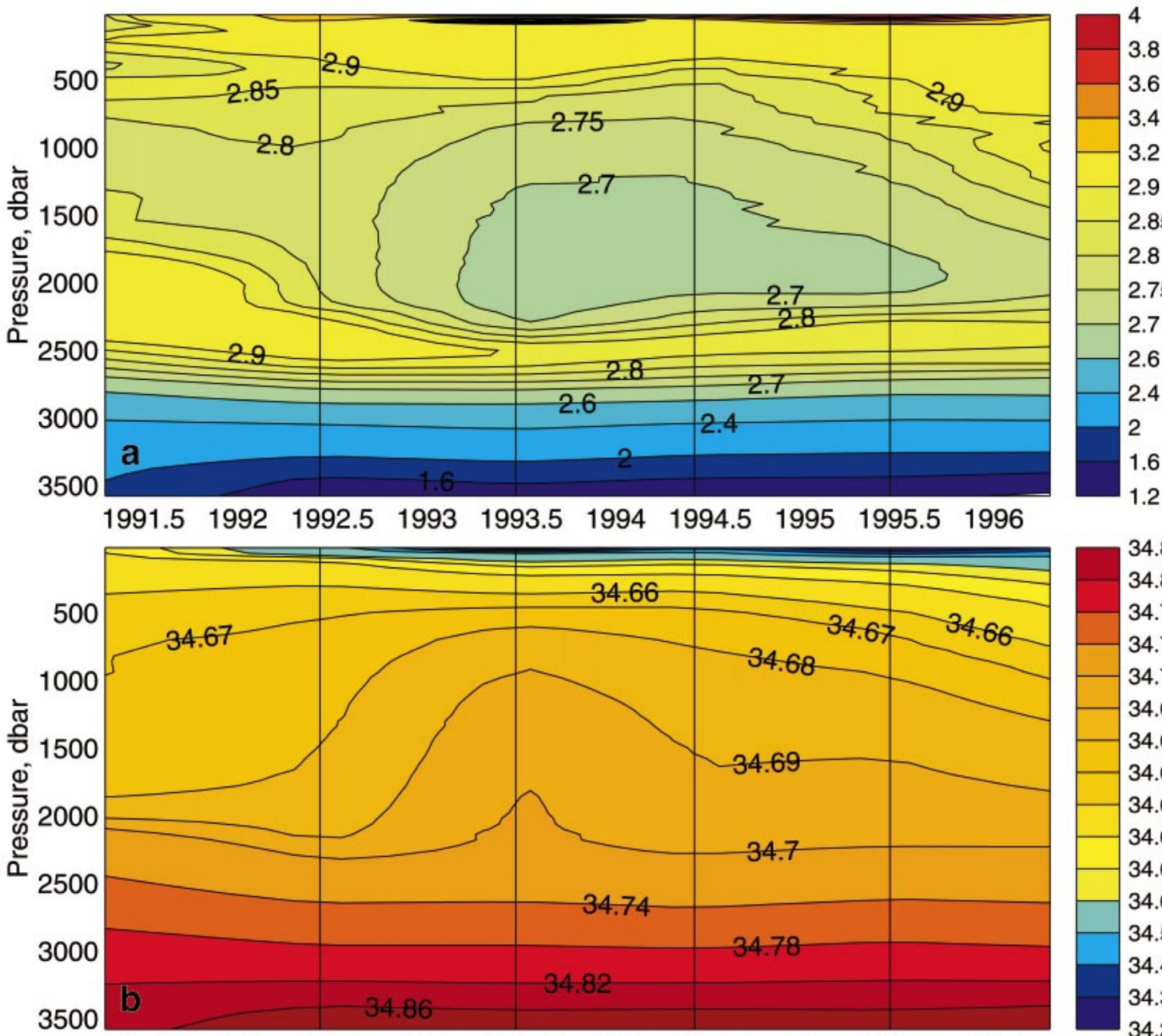

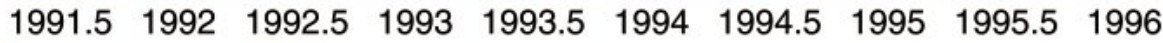

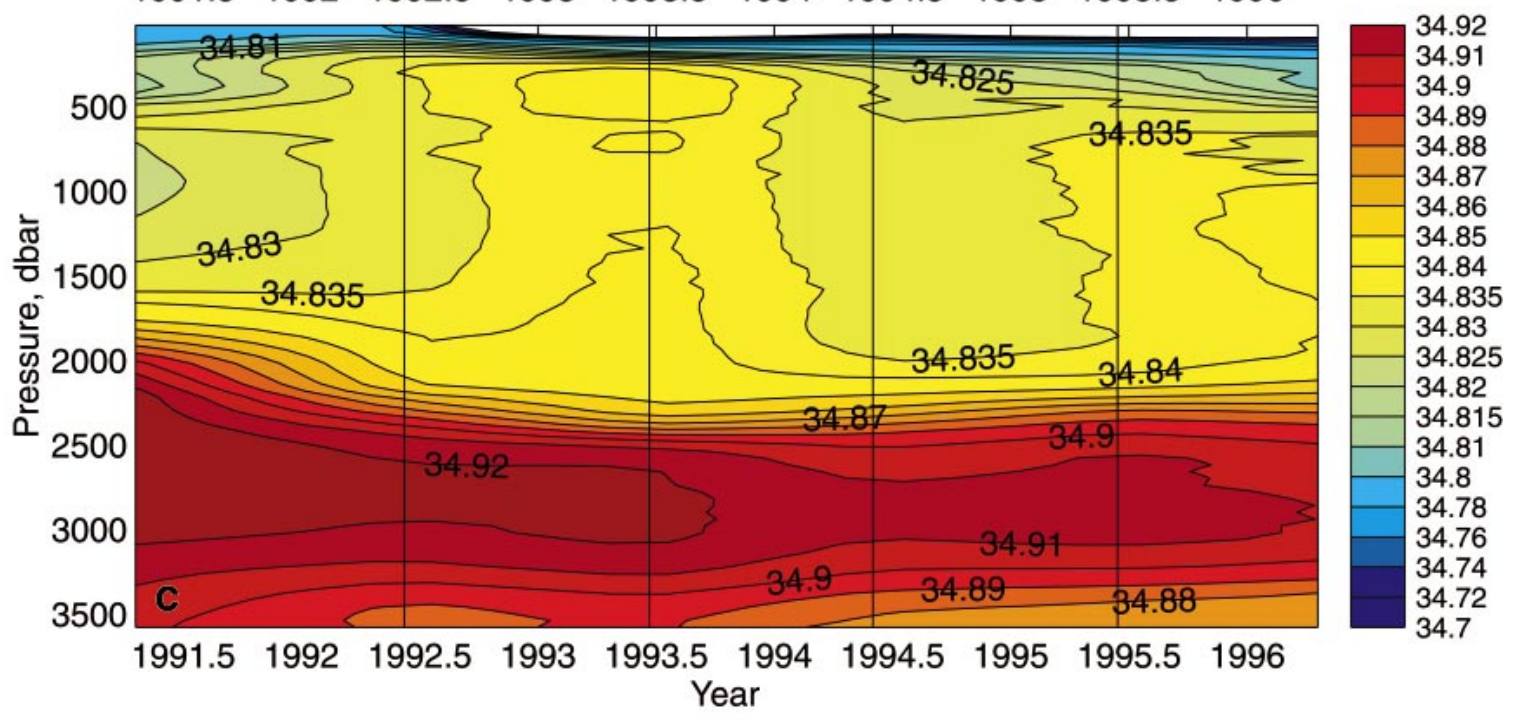

FIG. 9. Time-pressure sections of (a) potential temperature, (b) potential density anomaly $\left(\sigma_{1500}\right)$, and (c) salinity from the central Labrador Sea. Vertical lines show when the data were collected (typically in Jun). 


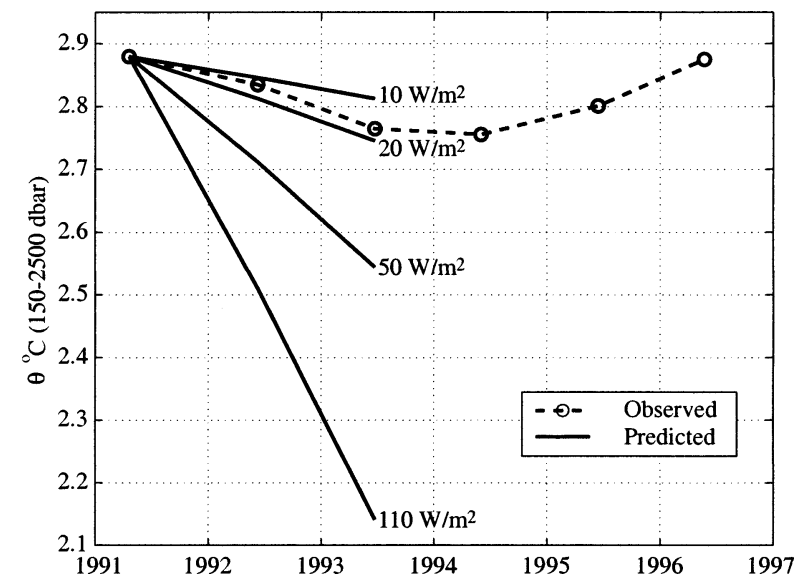

FIG. 10. A comparison of observed (broken line) and expected (solid lines) potential temperature in the 150-2500 dbar layer in the central Labrador Sea. The observed cooling between 1991 and 1993 implies an average heat loss of $15 \mathrm{~W} \mathrm{~m}^{-2}$ over that period. The predicted temperature curves for that period were computed by applying the indicated heat loss to the water column. The average heat loss between 1991 and 1993 (estimated from NCEP reanalysis) is $110 \mathrm{~W} \mathrm{~m}^{-2}$

ence of normalized sea level pressures between Lisbon, Portugal, and Stykkisholmur/Reykjavik, Iceland. The modulation of heat flux in the North Atlantic by the NAO is well documented (Lab Sea Group 1998; Dickson et al. 1996) and will not be discussed further. The atmospheric forcing does not increase monotonically between 1991 and 1993, whereas the temperature data suggest a monotonic increase in the depth of convection. These observations are consistent with the idea that the interior of the Labrador Sea in essence integrates in time the effect of atmospheric forcing, and thus responds more slowly to the relatively more variable surface forcing. This implies that convection in previous years preconditions the water column for the following winter (Marshall and Schott 1999).

\section{b. $3 \mathrm{He}$ time series}

Temporal evolution of [ $\left.{ }^{3} \mathrm{He}\right]$ (Fig. 12a) closely follows the temperature changes, with the tritiogenic $\left[{ }^{3} \mathrm{He}\right]$ of the LSW layer (1000-1500 dbar) remaining nearly constant, while that of the deeper layer (1500-2000 dbar) decreased by $\sim 0.5 \mathrm{TU}$ between 1991 and 1993 . The ${ }^{3} \mathrm{He}$ concentration of the 2000-2500 dbar layer decreased even more dramatically by $1 \mathrm{TU}$. This reduction was followed by an increase in the mean $\left[{ }^{3} \mathrm{He}\right]$ of the 1000-2500 dbar layer between 1994 and 1996. The ${ }^{3} \mathrm{He}$ concentration of the 500-1500 dbar layer shows a slight increase between 1991 and 1993, reflecting the balance between the (finite) rate at which tritiogenic ${ }^{3} \mathrm{He}$ can escape to the atmosphere during deep convection, and mixing with underlying waters with higher tritiogenic ${ }^{3} \mathrm{He}$ concentration. It is thus apparent that excess ${ }^{3} \mathrm{He}$ is a particularly sensitive indicator of the ventilation process, but is not reset to zero by convection (Fuchs
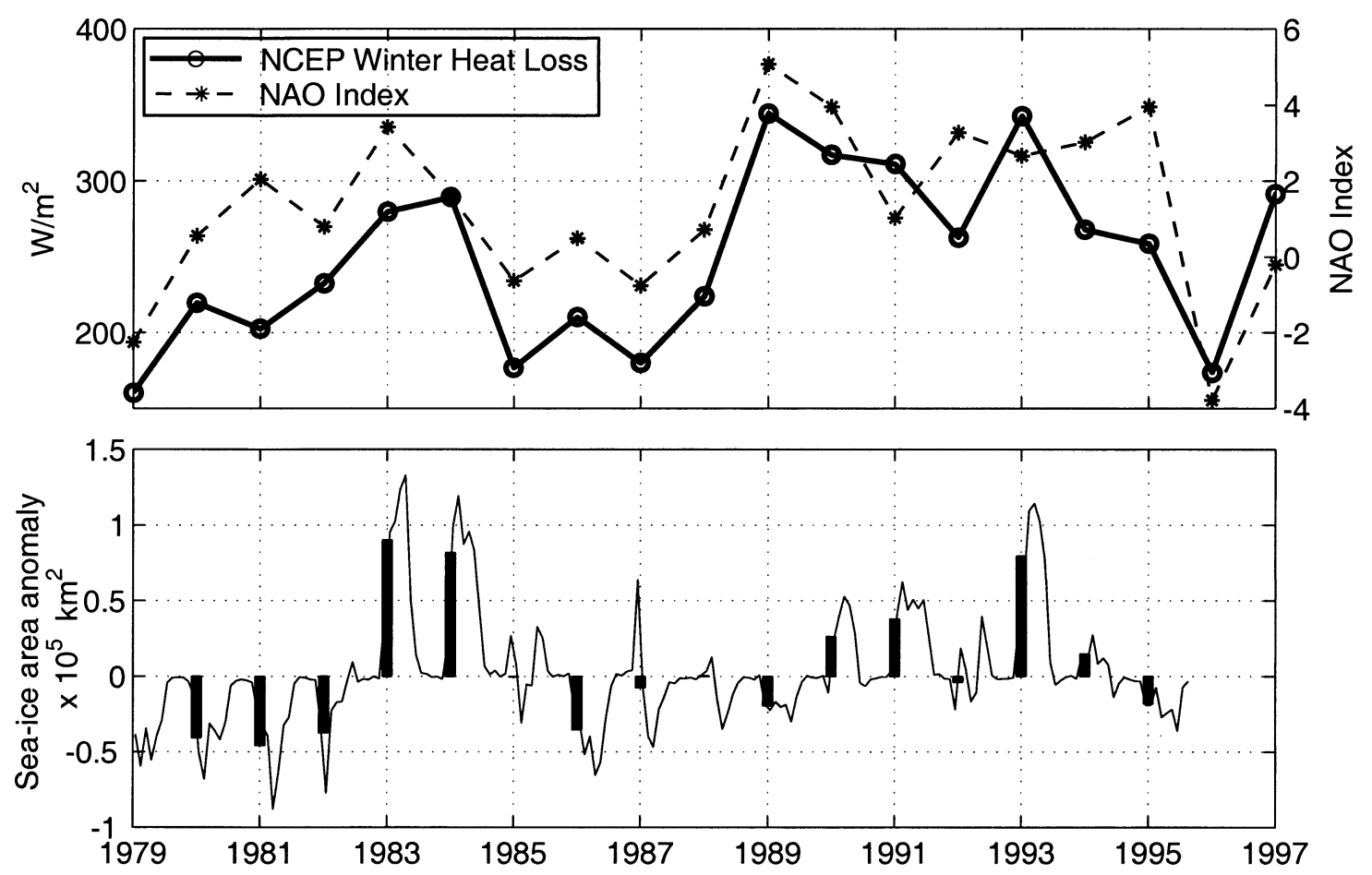

FIG. 11. (top) The time series of mean winter (DJFM) net heat flux (solid line) in the central Labrador Sea from the NCARNCEP reanalysis, and the winter index of NAO (broken line). (bottom) The time series of anomalies of sea ice extent on the Labrador shelf from SSM/I data. Vertical bars are average winter (DJFM) anomalies. 

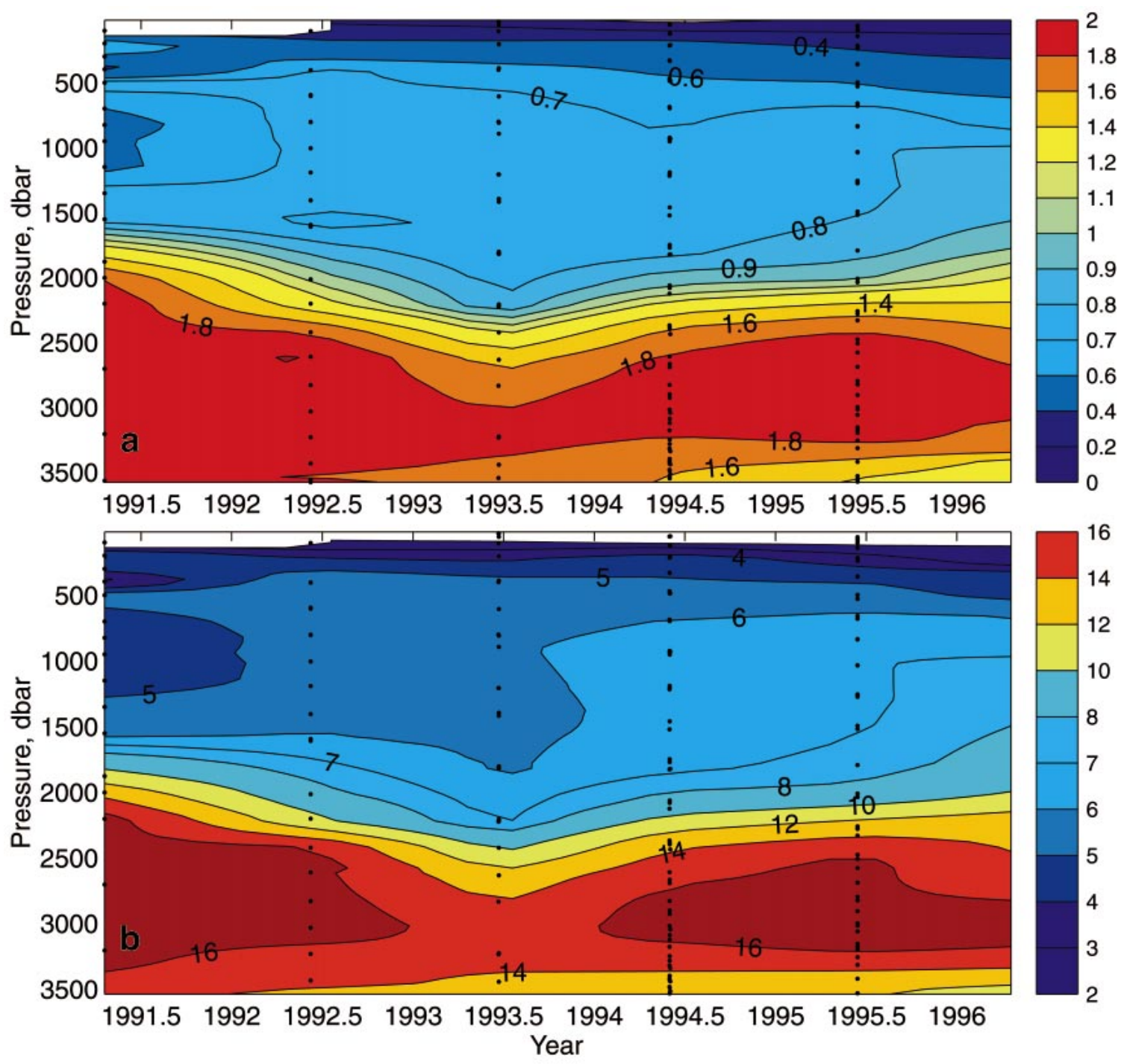

FIG. 12. Time-pressure sections of (a) tritiogenic ${ }^{3} \mathrm{He}$ concentration and (b) ${ }^{3} \mathrm{H}-{ }^{3} \mathrm{He}$ age in the central Labrador Sea. Dots show the time (typically in Jun) and pressure at which samples were collected.

et al. 1987). In particular, mixing with underlying and surrounding fluid with higher ${ }^{3} \mathrm{He}$ concentrations can complicate its interpretation.

The time evolution of $\theta$ and ${ }^{3} \mathrm{He}$ can be used to reconstruct (qualitatively) the time history of deep convection in the Labrador Sea in the 1990s. The ${ }^{3} \mathrm{He}$ concentration can decrease by gas exchange with the atmosphere during deep convection. Alternatively, it can increase by in situ decay of ${ }^{3} \mathrm{H}$ (at a rate of $\sim 0.1 \mathrm{TU}$ $\mathrm{yr}^{-1}$ for typical LSW ${ }^{3} \mathrm{H}$ concentrations of $1.5 \mathrm{TU}$ ) or by "excavation" of deeper layers (in particular, NEADW). Thus, it appears that there was increasing convection between 1991 and 1993 as the stratified upper part of NEADW was eroded, followed by a reduction in convective activity in 1994. Thereafter convection was restricted to shallower depths and probably did not penetrate below 800 dbar. These inferences are sup- ported by the time evolution of $\sigma_{1500}$ (Fig. 9b), which shows a sharp shoaling of the deeper isopycnals between 1991 and 1993, and following winter 1993/94 a more gradual deepening of the isopycnals in the upper 2000 dbar.

It is important to note that our inferred ventilation depth during winter $1994 / 95(<1000 \mathrm{~m})$ is quite different from the value cited by Lilly et al. (1999), who suggest that convection that winter penetrated to a depth of $1750 \mathrm{~m}$. This difference exists because our estimate, based on large-scale tracer budgets, refers to the depth to which the ocean was ventilated, while that of Lilly et al. (1999), which is based on evidence of convective plumes in a mooring record (May 1994-June 1995), refers to the depth to which these convective plumes penetrated. Given the large lateral variations in depth of convection (Lab Sea Group 1998; Lilly et al. 1999; 


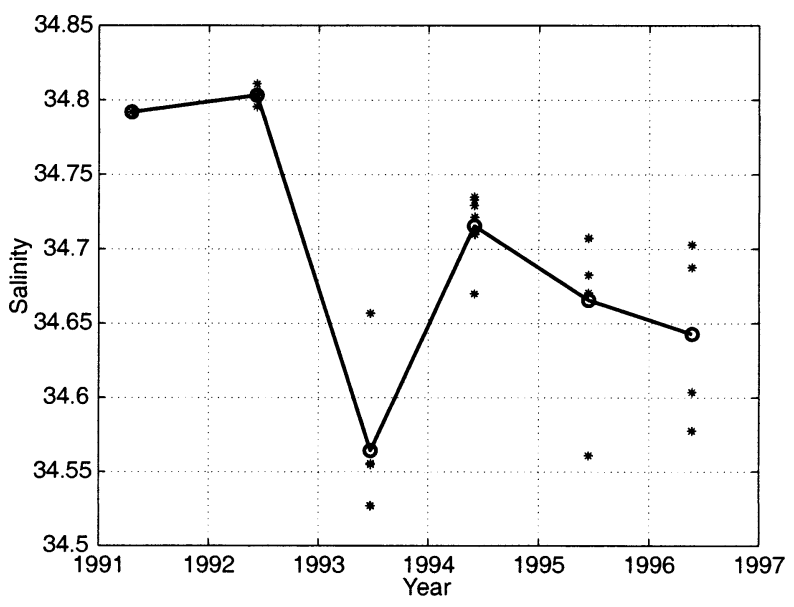

FIG. 13. Time series of average salinity (open circles) in the upper 150 dbar in the central Labrador Sea. Also shown (*) to illustrate the variability is the average salinity at individual stations.

Pickart et al. 2002), it is likely that convective events observed at a single location do not adequately capture the ventilation of LSW as diagnosed from tracer budgets.

\section{c. Salinity time series}

While the amplitudes of salinity changes (Fig. 9c) are small relative to changes in $\theta$ or ${ }^{3} \mathrm{He}$, they are consistent with the inferred history of convection described above. The onset of deeper convection in winter 1992 mixed down the fresher surface waters, thus reducing the salinity of the deep waters. The largest changes occur in the 1500-2000-dbar (0.02 psu) and 2000-2500-dbar (0.05 psu) layers. Like $\theta$, the salinity in the 500-1500dbar interval remained constant due to the competing influence of mixing down of fresher water and entrainment of saltier water from below. As the convection penetrated even deeper in $1993(\sim 2300 \mathrm{~m})$, eroding into the saltier NEADW, the salinity throughout the upper 2000 dbar increased. However, the mean salinity of the 150-2500-dbar interval remained virtually unchanged. Lazier (1995) has also noted the opposite trends in salinity in the deeper and shallower layers, especially during periods of increasing convective activity, and suggested that salt is conserved through vertical mixing.

An interesting feature is the sharp decrease in the salinity of the upper layer in June 1993 (Fig. 13). As discussed above, freshwater produced by melting of sea ice is sufficient to account for the observed summer freshening in the Labrador Sea. Consistent with this, we hypothesize that the strong atmospheric forcing in winter 1993 resulted in increased sea ice formation on the Labrador shelf (lower panel of Fig. 11). Subsequent melting of the sea ice would then increase the amplitude of the seasonal freshening.

It appears that the combined effects of excess freshwater and moderate atmospheric forcing resulted in shallower convection in $1994(<2000 \mathrm{~m})$. Convection in 1994 was still sufficiently robust to mix down the excess freshwater, thus reducing the salinity of the 1502000-dbar layer. As mentioned above, this robustness might have been due to preconditioning of the water column in previous years. After 1994, the data suggest that convection was restricted to the upper 500-800 m. As a result, the salinity of the upper layer decreased as freshwater accumulated, while that of the deeper water increased due to lateral mixing. This strong reduction in ventilation is consistent with the heat flux time series (Fig. 11), which shows that average winter heat flux in 1996 was less than half its 1993 value.

\section{d. $3 \mathrm{H}-3 \mathrm{He}$ age $\left(\tau_{t h}\right)$}

Finally, we discuss the time series of ${ }^{3} \mathrm{H}-{ }^{3} \mathrm{He}$ age (Fig. 12b). As was noted above, the ${ }^{3} \mathrm{H}-{ }^{3} \mathrm{He}$ ages depend not only on the intensity of convection ("ventilation rate") and entrainment of underlying older water, but also on mixing with recirculating waters in the boundary currents. Furthermore, the modeled ${ }^{3} \mathrm{H}-{ }^{3} \mathrm{He}$ age also undergoes a substantial seasonal cycle, decreasing in winter and increasing through the remainder of the year, both by in situ decay of ${ }^{3} \mathrm{H}$ to ${ }^{3} \mathrm{He}$ and by mixing with the ambient and boundary fluid. Given these complications, our interpretation of the tracer-derived ages as "ventilation" or "residence" times will be largely qualitative.

During the early 1990s, $\tau_{t h}$ of LSW (1000-1500 dbar) increased from $5 \mathrm{yr}$ in 1991 to $6 \mathrm{yr}$ in 1993. This increase in $\tau_{t h}$ occurred even as convection penetrated to greater depths. In this case, mixing with older waters with higher excess ${ }^{3} \mathrm{He}$ concentrations coupled with a finite gas exchange velocity shifted the $\tau_{t h}$ toward higher values. Between 1991 and 1993, $\tau_{t h}$ of the 1500-2000dbar layer decreased from $\sim 9$ to $6 \mathrm{yr}$, while the mean $\tau_{\text {th }}$ of the 2000-2500-dbar layer decreased from 16 to 8.5 yr. After $1994, \tau_{t h}$ shows a systematic increase below $\approx 800 \mathrm{dbar}$ and, as convection was restricted to progressively shallower depths, a decrease in the upper 500 dbar. This latter result is consistent with the notion that as the winter mixed layer becomes shallower, tritiogenic ${ }^{3} \mathrm{He}$ is lost more effectively.

Between 1994 and 1996 the ${ }^{3} \mathrm{H}-{ }^{3} \mathrm{He}$ age of the $1000-$ 2000 -dbar layer changed by nearly 2 yr over that 2 -yr period. Furthermore, the increase in ${ }^{3} \mathrm{He}$ between 1994 and 1996 is roughly $0.2 \mathrm{TU}$, which can be explained almost entirely due to tritium decay (tritium decays at roughly $6 \%$ per year; for typical LSW ${ }^{3} \mathrm{H}$ concentrations decay will produce $\sim 0.1$ TU of tritiogenic ${ }^{3} \mathrm{He}$ per year). These data thus give the impression that this layer is responding as a stagnant water body. However, as is clearly seen by the increase in $\theta$ and $S$ after 1994 of waters below $\sim 1000$ dbar (Fig. 9), this layer is not truly stagnant and exchanges tracers with the boundaries both via an eddy-induced circulation (see below) and isopycnal stirring by eddies. 


\section{Role of eddies in the Labrador Sea}

The time series presented above shows that the central Labrador Sea exchanges heat and salt very efficiently with the warmer and saltier boundary currents. In the absence of Eulerian mean currents it is clear that eddies must play an important role in this exchange process. In a recent study, Khatiwala and Visbeck (2000) proposed the existence of an eddy-induced "overturning" circulation in the Labrador Sea and estimated its strength using hydrographic data. Here we provide additional evidence in support of the proposed eddy-induced circulation and discuss its implications in more detail. We first review the notion of an eddy-induced circulation.

\section{a. The eddy-induced circulation in the Labrador Sea}

Guided by previous work (e.g., Gill et al. 1974; Gent et al. 1995; Visbeck et al. 1997), Khatiwala and Visbeck (2000) suggest that the combined effects of buoyancy and wind forcing result in a buildup of available potential energy (APE), which is then released via the action of baroclinic eddies. They propose that this release of APE due to slumping of isopycnals drives an eddy-induced "overturning" circulation that is an important aspect of the adjustment process following deep convection. The strength of this circulation could be inferred from hydrographic data by assuming that away from the mixed layer the eddy-induced circulation is adiabatic; that is,

$$
\frac{\partial \sigma_{\theta}}{\partial t}+\mathbf{u} \cdot \nabla \sigma_{\theta}=0
$$

where $\sigma_{\theta}$ is the potential density anomaly and $\mathbf{u}$ the velocity, which can be split into mean $(\overline{\mathbf{u}})$ and timevarying or "eddy" $\left(\mathbf{u}^{*}\right)$ components. The proposed eddy-induced circulation is illustrated in Fig. 14.

Applying the above equation to a mean annual cycle of $\sigma_{\theta}$ in the central Labrador Sea (1964-74) and invoking continuity, they infer a vertical eddy-induced velocity, $w^{*} \approx-10^{-3} \mathrm{~cm} \mathrm{~s}^{-1}\left(\sim 1 \mathrm{~m} \mathrm{day}^{-1}\right)$, a surface intensified inflow velocity, $v_{s}^{*} \approx 0.5 \mathrm{~cm} \mathrm{~s}^{-1}$, and an outflow velocity (at depth), $v_{d}^{*} \approx 0.1-0.2 \mathrm{~cm} \mathrm{~s}^{-1}$. Note that a $v_{d}^{*}$ of this magnitude implies an isopycnal exchange coefficient $\kappa \sim v_{d}^{*} L$ greater than $300-600 \mathrm{~m}^{2}$ $\mathrm{s}^{-1}(L=300 \mathrm{~km}$, half the basin width) and considerably larger toward the surface.

\section{b. Deep eddy-induced circulation}

One drawback of the technique employed by Khatiwala and Visbeck (2000) to quantify the eddy-induced circulation is that below $\sim 1000 \mathrm{~m}$ vertical gradients in density are extremely small, and thus vertical eddy-induced motion would not produce any local changes in density. Thus, their technique cannot detect eddy-induced motion in the homogeneous core of LSW. Kha-

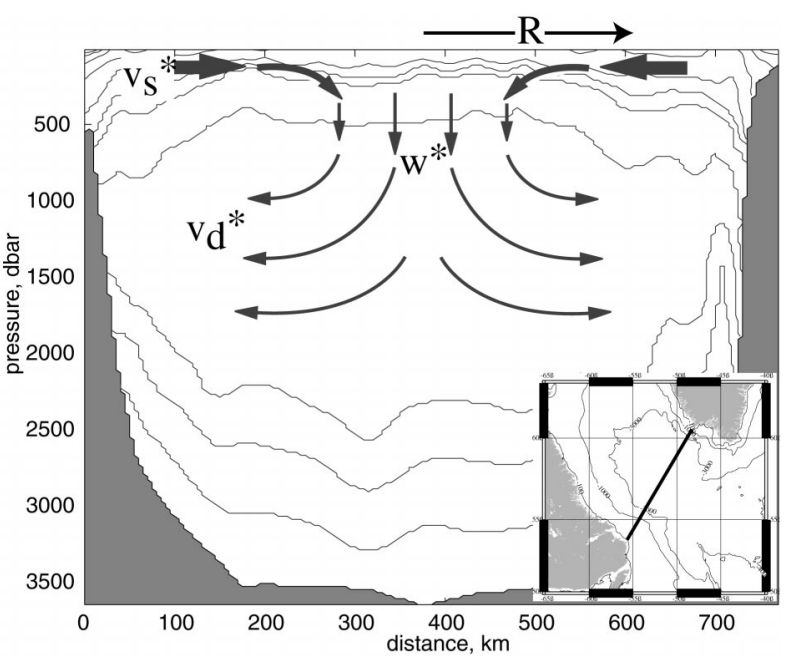

FIG. 14. Schematic of eddy-induced circulation in the Labrador Sea from Khatiwala and Visbeck (2000). The schematic is superimposed on a potential density section (see inset map for position of section) across the Labrador Sea. The proposed circulation consists of a surfaced intensified inflow $\left(v_{s}^{*}\right)$, sinking motion in the interior $\left(w^{*}\right)$, and an "outflow" at depth $\left(v_{d}^{*}\right)$.

tiwala and Visbeck (2000) attribute the absence of a signal below $1000 \mathrm{~m}$ to weak convection during the 1964-74 period (Lazier 1995). This is probably reasonable, but we believe that in years of more intense convection the eddy-induced circulation likely extends deeper. Here we present indirect evidence for such a deep eddy-induced circulation in the central Labrador Sea.

The upper panel in Fig. 15 shows the $\sigma_{\theta}$ across the Labrador Sea in June 1994, while the lower panel shows the $\sigma_{\theta}$ in May of 1995. As discussed above, tracer data suggest that convection in winter 1994 reached $\sim 2000$ $\mathrm{m}$, while that in 1995 was restricted to the upper 800 m. Evidently, in both years the density between 1000 $2000 \mathrm{~m}$ is very uniform. Next, note the changes in the $27.77-27.78 \mathrm{~kg} \mathrm{~m}^{-3} \sigma_{\theta}$ layer. In 1994 there are strong horizontal gradients in the thickness of this layer, particularly near the boundary. By the following year (1995) these gradients have been smoothed out and the 27.78 isopycnal (for example) is noticeably flatter. These changes are consistent with the notion that the eddy-induced flow effectively transports fluid adiabatically so as to remove such gradients (Gent et al. 1995). In the process mass is rearranged so as to reduce the available potential energy. This interpretation of the density changes can be quantified as follows. In the central part of the basin the 27.77 isopycnal moved down by $\sim 100 \mathrm{~m}$ between 1994 and 1995, while the 27.78 isopycnal moved up by $\sim 400 \mathrm{~m}$, implying vertically convergent motion in the core LSW layer. The implied vertical velocity for the lower isopycnal is $\sim 1$ $\mathrm{m}$ day $^{-1}$, of similar magnitude (but of opposite sign) to that estimated by Khatiwala and Visbeck (2000). If we consider a small cylinder in the central Labrador Sea of 
1994
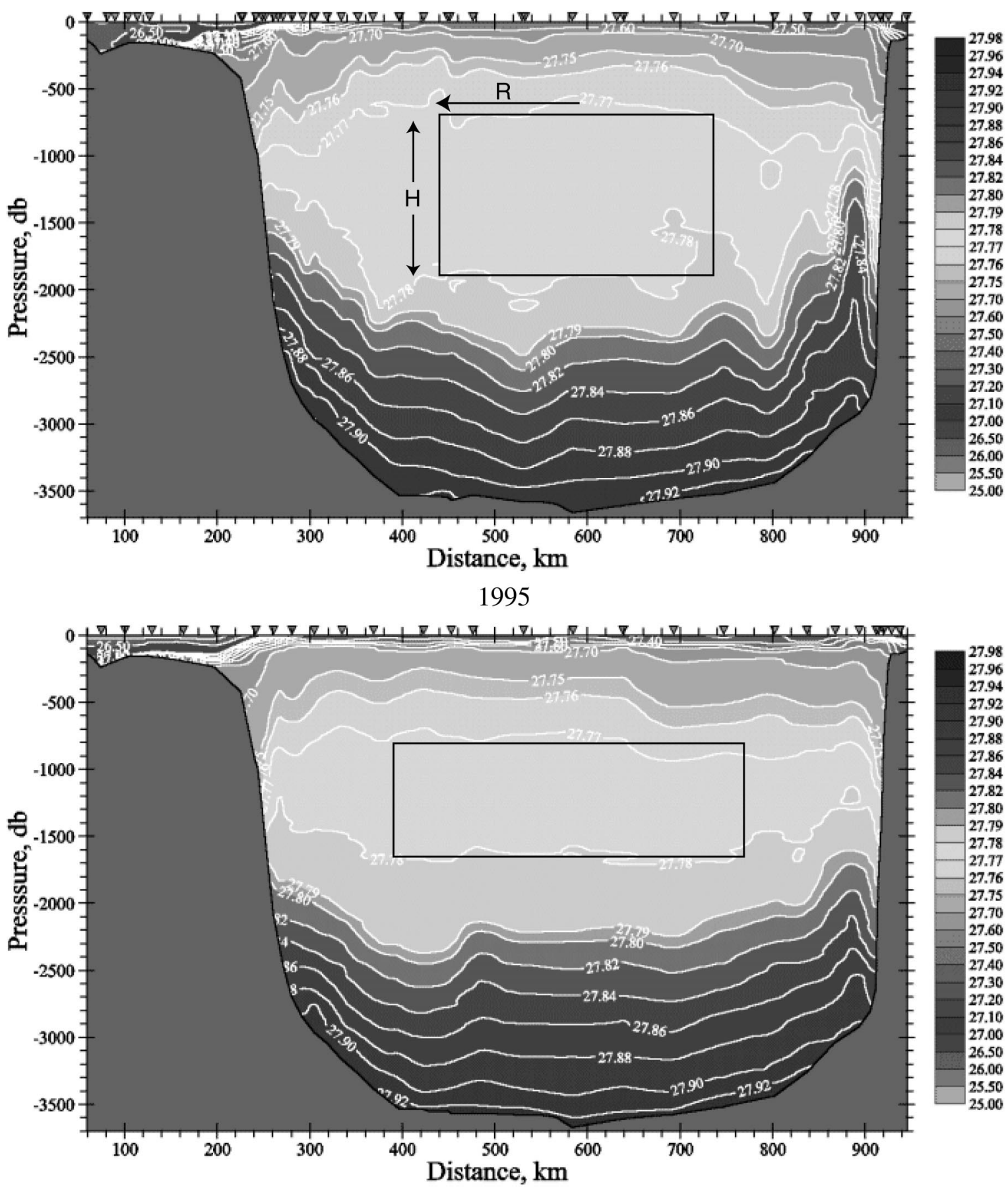

FIG. 15. Potential density section across the Labrador Sea from Jun 1994 (top) and May 1995 (bottom). The rectangular boxes illustrate how the volume between isopycnals is conserved. Density sections provided by Igor Yashayev.

thickness $H$ and radius $R$, bounded above by the 27.77 and below by the 27.78 isopycnals (boxes in Fig. 15), it is being squeezed in the vertical and thus must expand radially to conserve volume. If, following Khatiwala and Visbeck (2000), we invoke azimuthal symmetry for the central Labrador Sea, we have

$$
\frac{d\left(\pi R^{2} H\right)}{d t}=0
$$

or rearranging,

$$
v^{*} \sim \frac{d R}{d t}=-\frac{R}{2 H} \frac{d H}{d t} .
$$


From Fig. 15 we see that $R \approx 150 \mathrm{~km}$ and $H$ changes by roughly $500 \mathrm{~m}$ over one year (from 1300 to $800 \mathrm{~m}$ ). Substituting numerical values we get

$$
v^{*} \sim \frac{d R}{d t} \sim 0.1 \mathrm{~cm} \mathrm{~s}^{-1} .
$$

This value is surprisingly similar to the value of $v_{d}^{*}$ estimated by Khatiwala and Visbeck (2000) for the central Labrador Sea above $1000 \mathrm{~m}$. The above arguments are admittedly crude and lacking in rigor, but not unreasonable given the limited data available. In particular, they suggest that geostrophic eddies transport newly ventilated LSW toward the boundaries where they interact with the boundary currents. This provides a physical mechanism by which LSW is "flushed" out of the Labrador Sea. In the 27.77-27.78 layer, the radially outward volume flux is of $O(1 \mathrm{~Sv})$.

\section{c. Freshwater transport}

In section 6 we showed that the salinity decrease between March and September in the upper $100 \mathrm{~m}$ of the central Labrador Sea corresponds to a freshwater input of $\sim 60 \mathrm{~cm}$, with sea ice meltwater being the likely source. Since much of the sea ice melts on the Labrador shelf or upstream in Baffin Bay and Davis Strait, this raises the question of how the interior of the Labrador Sea is freshened during summer. It is likely, as has been speculated in previous studies (e.g., Lab Sea Group 1998; Lilly et al. 1999), that eddies are likely to be responsible for transport of freshwater from the lowsalinity boundary currents into the interior. Here, we estimate the freshwater transport implied by the eddyinduced circulation discussed above. We assume that the transport takes place in a near-surface layer of thickness $h(\sim 100 \mathrm{~m}$, the depth to which the summer decrease in salinity is restricted) with eddy-induced velocity $v_{s}^{*}$ [estimated by Khatiwala and Visbeck (2000) to be roughly $0.5 \mathrm{~cm} \mathrm{~s}^{-1}$. Then the flux of salt, $Q_{s}$, into an interior region of radius $R$ (Fig. 14) is given by

$$
Q_{s} \sim \frac{v_{s}^{*} 2 h \Delta S \rho_{o}}{1000 R},
$$

where $\Delta S$ is the average salinity difference between the interior and boundaries $(\sim 1 \mathrm{psu})$ and $\rho_{o}$ a reference sea water density. This salt flux is equivalent to an addition of freshwater to the central Labrador Sea. The values mentioned above give a salt flux $Q_{s} \approx 3 \times 10^{-6} \mathrm{~kg}$ $\mathrm{m}^{-2} \mathrm{~s}^{-1}$. Over a period of 6 months (March-September) this is equivalent to an addition of $\sim 140 \mathrm{~cm}$ of freshwater over the central Labrador Sea, which, within the various approximations, indicates that eddy-induced exchange is a viable mechanism for transporting freshwater into the interior of the Labrador Sea.

\section{d. Formation rate of $L S W$}

Khatiwala and Visbeck (2000) infer the strength of the eddy-induced overturning circulation to be roughly 2-3 Sv. It is useful to compare this value with the formation rate of LSW as diagnosed from surface buoyancy fluxes (Walin 1982; Speer and Tziperman 1992; Marshall et al. 1999). Fluxes of heat and freshwater at the surface of the ocean serve to convert water from one density into another. The downward flux of density is given by

$$
f=-\frac{\alpha Q}{c_{p}}+\beta(E-P) S,
$$

where $Q$ is the net heat flux, $\alpha$ and $\beta$ are the thermal expansion and haline contraction coefficients, respectively, $S$ the salinity at the sea surface (SSS), and $E-$ $P$ the evaporation minus precipitation rate (in $\mathrm{kg} \mathrm{m}^{-2}$ $\left.\mathrm{s}^{-1}\right)$. The water mass transformation, $F(\rho)$, is defined by

$$
F(\rho)=f \frac{d A}{d \rho} ;
$$

$F(\rho)$ (Tziperman 1986) is generally interpreted as the volume flux across the isopycnal $\rho$ due to air-sea buoyancy forcing. The rate at which water accumulates between any two isopycnals $\rho$ and $\rho+d \rho$ is then

$$
M(\rho) d \rho=-[F(\rho+d \rho)-F(\rho)],
$$

where $M(\rho)$ is the formation rate per unit density. Following Speer and Tziperman (1992) we have computed $F$ for the Labrador Sea $\left(50^{\circ}-65^{\circ} \mathrm{N}, 40^{\circ}-70^{\circ} \mathrm{W}\right)$. For comparison, $F$ was calculated using fluxes derived from both the NCEP reanalysis (monthly means, 1958-99) and a monthly mean climatology (da Silva et al. 1994). For both calculations, sea surface density was computed from the Levitus (Levitus and Boyer 1994; Levitus et al. 1994) sea surface temperature and salinity climatology. The resulting water mass transformation rate (in $\mathrm{Sv}$ ) is shown in Fig. 16 as a function of density anomaly $(\sigma)$. For $F$ calculated from NCEP, we only show two years to illustrate the range of values that occurs (1972 for the upper bound and 1977 for the lower bound). Recent work (Renfrew et al. 2002) suggests that the NCEP model overestimates the bulk fluxes substantially, and this must be kept in mind when interpreting the transformation rates presented here. In contrast, fluxes from the European Centre for Medium-Range Forecasts (ECMWF) operational analyses appear to be more accurate, but these data were not available to us.

Figure 17 shows a time series of the formation of waters of density $\sigma_{\theta}=27.7-27.9$. The mean formation rates are $2.7 \mathrm{~Sv}$ and $1.7 \mathrm{~Sv}$ for NCEP and da Silva, respectively. The NCEP average hides large variations (ranging from $1 \mathrm{~Sv}$ in 1979 to $5 \mathrm{~Sv}$ in 1972). The important point we wish to make here is that the (thermodynamic) formation rate is of the order of 2-3 Sv, similar to the 2-4 Sv estimated formation rate of Labrador Sea Water (Lab Sea Group 1998), and quite close 


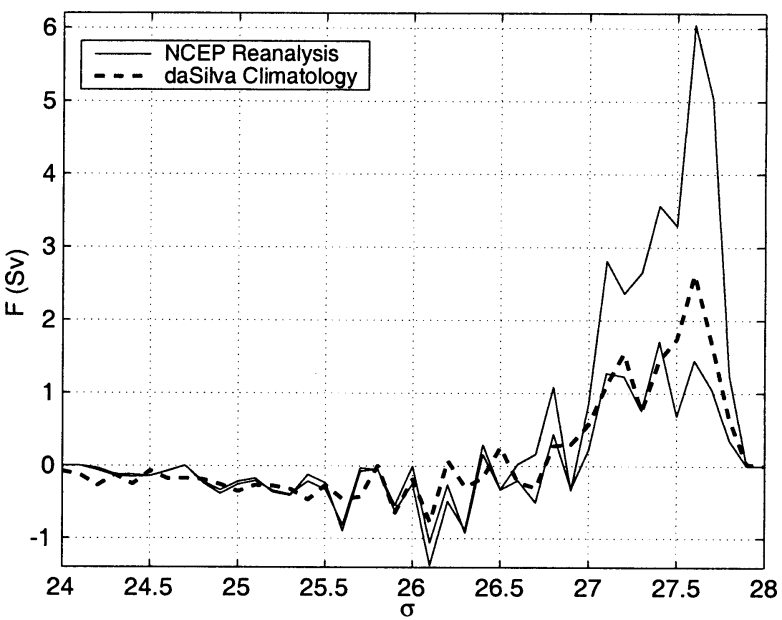

FIG. 16. Water mass transformation rate, $F$ (Sv) for the Labrador Sea computed using fluxes derived from NCEP (the two solid lines indicate the maximum and minimum values) and the da Silva climatology (broken line).

to the volume of fluid transported by the overturning circulation. While the relationship between the overturning circulation and the formation rate is not entirely clear, it is perhaps not surprising that these values are so similar. A net annual formation of water of a certain density class by surface fluxes requires a surface convergence of fluid at the same rate. If we imagine that this newly "formed" fluid sinks from the formation site and is transported toward the boundaries by the eddyinduced circulation, there is then a close association between the formation rate and the overturning circulation. This is a connection that needs to be studied further.

One final point to note is that we calculate the formation rate for only a small region, and our values are considerably smaller than those obtained by previous studies (e.g., Speer and Tziperman, 1992; Marsh 2000) where the calculation was performed for the entire North Atlantic. Clearly, waters of similar density outcrop elsewhere in the North Atlantic (in particular the Irminger Sea and the northeast Atlantic), but this contribution is excluded from our calculation [see also Speer et al. (1995)].

\section{Conclusions}

We have presented and interpreted time series of hydrographic and transient tracer observations from the central Labrador Sea to document interannual variations in convective activity in the 1990s. This variability is a result of various interacting factors, including surface buoyancy forcing modulated by large-scale atmospheric patterns such as the NAO, preconditioning of the water column from previous winters, and the mixing into the interior of sea ice meltwater from the shelves. The data also provide strong evidence for the efficient exchange of heat, salt, and other tracers via eddies between the

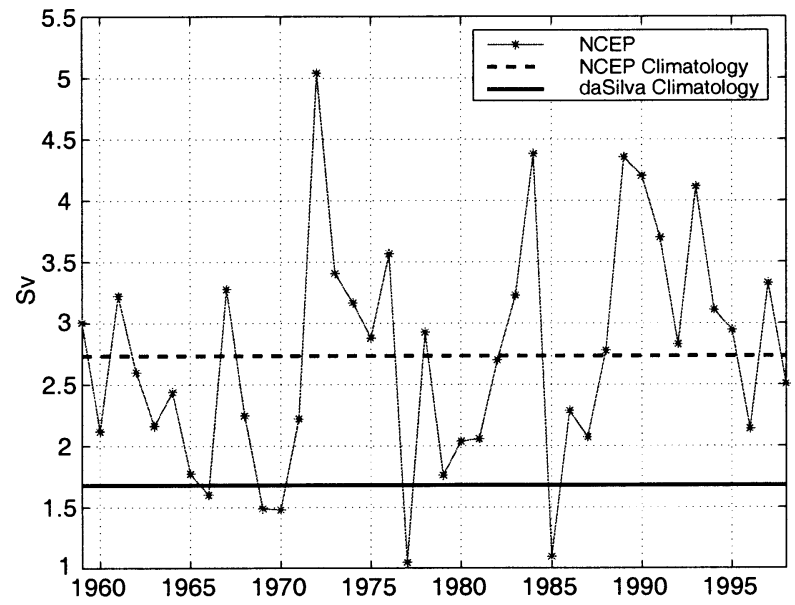

FIG. 17. Time series of annual mean water mass formation rate (Sv) into $\sigma_{\theta}=27.7-27.9$ density class computed using NCEP fluxes The average formation rate $(2.7 \mathrm{~Sv})$ is shown by the thick dashed line. A year extends from Dec (of previous year) through Nov. Also shown (thick solid line) is the formation rate $(1.7 \mathrm{~Sv})$ calculated from da Silva fluxes.

central Labrador Sea and the boundaries. This exchange process has to be taken into account in the interpretation of tracer observations. Furthermore, our results highlight the difficulty of deriving tracer source functions, which are frequently utilized in numerical modeling studies of the thermohaline circulation, simply from models of air-sea exchange, and demonstrate the value of continued measurements in the "source" region. The eddies could also play an important role in transporting newly ventilated LSW out of the region. Finally, the importance of geostrophic eddies makes the task of numerically simulating the Labrador Sea a challenging one both from the point of defining correct boundary conditions for tracers as well as accurately representing subgrid-scale processes.

Acknowledgments. The tritium and helium isotope data were collected on cruises conducted by the Bedford Institute of Oceanography. We would like to thank Allyn Clarke, John Lazier, and Peter Jones for generous provision of ship time and accommodation for personnel, and Igor Yashayev for providing the density sections shown in Fig. 15. G. Bönisch performed part of the tritium and helium isotope measurements in the L-DEO noble gas laboratory. Dee Breger, Brenda Ekwurzel, Jean Hanley, and Evelyn Kohandoust participated in cruises to the Labrador Sea to collect tracer samples. Chuck McNally performed part of the helium isotope sample extractions. This research was supported by the National Oceanographic and Atmospheric Administration through Grants NA46GP0112 and NA86GP0357 (ACCP). MV was funded by ONR under Grant N0001498-1-0302. The W. M. Keck Foundation provided a generous grant for the establishment of the L-DEO Noble Gas Laboratory. 


\section{REFERENCES}

Chapman, D. C., and R. C. Beardsley, 1989: On the origin of shelf water in the Middle Atlantic Bight. J. Phys. Oceanogr., 19, 389391.

Clarke, R. A., and J.-C. Gascard, 1983: The formation of Labrador Sea Water. Part I: Large scale processes. J. Phys. Oceanogr., 13, 1764-1788.

da Silva, A., A. C. Young, and S. Levitus, 1994: Algorithms and Procedures. Vol. 1, Atlas of Surface Marine Data 1994, NOAA Atlas NESDIS 6, $83 \mathrm{pp}$.

Dickson, R. R., J. Meincke, S.-A. Malmberg, and A. J. Lee, 1988: The "Great Salinity Anomaly" in the northern North Atlantic 19681982. Progress in Oceanography, Vol. 20, Pergamon, 103-151.

_ J. Lazier, J. Meincke, P. Rhines, and J. Swift, 1996: Long-term coordinated changes in the convective activity of the North Atlantic. Progress in Oceanography, Vol. 38, Pergamon, 241-295.

Doney, S. C., W. J. Jenkins, and H. G. Östlund, 1993: A tritium budget for the North Atlantic. J. Geophys. Res., 98, 18 06918081 .

Dreisigacker, E., and W. Roether, 1978: Tritium and ${ }^{90} \mathrm{Sr}$ in North Atlantic surface water. Earth Planet. Sci. Lett., 38, 301-312.

Fuchs, G. W., W. Roether, and P. Schlosser, 1987: Excess ${ }^{3} \mathrm{He}$ in the ocean surface layer. J. Geophys. Res., 92, 6559-6568.

Gent, P. R., and J. C. McWilliams, 1990: Isopycnal mixing in ocean circulation models. J. Phys. Oceanogr., 20, 150-155.

_, J. Willebrand, T. J. McDougall, and J. C. McWilliams, 1995: Parameterizing eddy-induced tracer transports in ocean circulation models. J. Phys. Oceanogr., 25, 463-474.

Gill, A. E., J. S. A. Green, and A. J. Simmons, 1974: Energy partition in the large-scale ocean circulation and the production of midocean eddies. Deep-Sea Res., 21, 499-528.

Holzer, M., and T. M. Hall, 2000: Transit-time and tracer-age distributions in geophysical flows. J. Atmos. Sci., 57, 3539-3558.

Hurrell, J., 1995: Decadal trends in the North Atlantic Oscillation: Regional temperatures and precipitation. Science, 269, 676-679.

Ice Climatology Services, 1992: Ice thickness climatology, 19611990 normals. Environment Canada Rep. En57-28/1961-1990, $66 \mathrm{pp}$.

Ingram, R. G., and S. Prinsenberg, 1998: Coastal oceanography of Hudson Bay and surrounding eastern Canadian Arctic waters. The Sea, A. R. Robinson and K. H. Brink, Eds., Vol. 11, Regional Studies and Syntheses, John Wiley, 835-861.

Inland Waters Directorate, 1991: Historical streamflow summary, Atlantic Provinces to 1990. Environment Canada, 294 pp.

Jenkins, W. J., and W. B. Clarke, 1976: The distribution of ${ }^{3} \mathrm{He}$ in the western Atlantic Ocean. Deep-Sea Res., 23, 481-494.

Kalnay, E., and Coauthors, 1996: The NCEP/NCAR 40-Year Reanalysis Project. Bull. Amer. Meteor. Soc., 77, 437-471.

Khatiwala, S., 2000: A tracer and modeling study of the Labrador Sea. Ph.D. thesis, Columbia University, $156 \mathrm{pp}$.

- and M. Visbeck, 2000: An estimate of the eddy-induced circulation in the Labrador Sea. Geophys. Res. Lett., 27, 22772280

— R. G. Fairbanks, and R. W. Houghton, 1999: Freshwater sources to the coastal ocean off northeastern North America: Evidence from $\mathrm{H}_{2}{ }^{18} \mathrm{O} / \mathrm{H}_{2}{ }^{16} \mathrm{O}$. J. Geophys. Res., 104, 18 241-18 255.

- M. Visbeck, and P. Schlosser, 2001: Age tracers in an ocean GCM. Deep-Sea Res. I, 48, 1423-1441.

Lab Sea Group, 1998: The Labrador Sea Deep Convection Experiment. Bull. Amer. Meteor. Soc., 79, 2033-2058.

Lazier, J. R. N., 1973: The renewal of Labrador Sea Water. DeepSea Res., 20, 341-353.

- 1980: Oceanographic conditions at Ocean Weather Ship Bravo, 1964-1974. Atmos.-Ocean, 18, 227-238.

, 1982: Seasonal variability of temperature and salinity in the Labrador Current. J. Mar. Res., 40 (Suppl.), 341-356.

, 1995: The salinity decrease in the Labrador Sea over the past thirty years. Natural Climate Variability on Decade-to-Century
Time Scales, D. G. Martinson et al., Eds., National Research Council, 295-304.

- , and D. G. Wright, 1993: Annual velocity variations in the Labrador Current. J. Phys. Oceanogr., 23, 659-678.

Levitus, S., and T. P. Boyer, 1994: Temperature. Vol. 4, World Ocean Atlas 1994, NOAA Atlas NESDIS 4, 117 pp.

_- R. Burgett, and T. P. Boyer, 1994: Salinity. Vol. 3, World Ocean Atlas 1994, NOAA Atlas NESDIS 3, 99 pp.

Lilly, J. M., P. B. Rhines, M. Visbeck, R. Davis, J. R. N. Lazier, F. Schott, and D. Farmer, 1999: Observing deep convection in the Labrador Sea during winter 1994/95. J. Phys. Oceanogr., 29, 2065-2098.

Loder, J. W., B. Petrie, and G. Gawarkiewicz, 1998: The coastal ocean off northeastern North America: A large-scale view. The Global Coastal Ocean: Regional Studies and Syntheses, A. R. Robinson and K. H. Brink, Eds., Vol. 11, The Sea, John Wiley, 105-133.

Ludin, A., R. Weppernig, G. Bönisch, and P. Schlosser, 1998: Mass spectrometric measurement of helium isotopes and tritium in water samples. Lamont-Doherty Earth Observatory Tech. Rep. 98-6, 42 pp.

Marsh, R., 2000: Recent variability of the North Atlantic thermohaline circulation inferred from surface heat and freshwater fluxes. J. Climate, 13, 3239-3260.

Marshall, J., and F. Schott, 1999: Open-ocean convection: Observations, theory and models. Rev. Geophys., 37, 1-64.

_ _ D. Jamous, and J. Nilsson, 1999: Reconciling thermodynamic and dynamic methods of computation of water-mass transformation rates. Deep-Sea Res. I, 46, 545-572.

McKee, T. K., R. S. Pickart, and W. M. Smethie, 1995: Hydrographic data from Endeavour 223: Formation and spreading of the shallow component of the North Atlantic Deep Western Boundary Current. Woods Hole Oceanographic Institution Tech. Rep. WHOI-95-07, $119 \mathrm{pp}$.

Myers, R. A., S. A. Akenhead, and K. Drinkwater, 1990: The influence of Hudson Bay runoff and ice-melt on the salinity of the inner Newfoundland Shelf. Atmos.-Ocean, 28, 241-256.

Pickart, R. S., D. J. Torres, and R. A. Clarke, 2002: Hydrography of the Labrador Sea during active convection. J. Phys. Oceanogr., 32, 428-457.

Renfrew, I. A., G. W. K. Moore, P. S. Guest, and K. Bumke, 2002: A comparison of surface layer and surface turbulent flux observations over the Labrador Sea with ECMWF analyses and NCEP reanalyses. J. Phys. Oceanogr., 32, 383-400.

Roether, W., 1967: Estimating the tritium input to groundwater from wine samples: Groundwater and direct run-off contribution to Central European surface waters. Isotopes in Hydrology, Vienna, Austria, IAEA, 73-91.

Schlosser, P., G. Bönisch, B. Kromer, K. O. Münnich, and K. P Koltermann, 1990: Ventilation rates of the waters in the Nansen Basin of the Arctic Ocean derived from a multi-tracer approach. J. Geophys. Res., 95, 3265-3272.

Seager, R., M. B. Blumenthal, and Y. Kushnir, 1995: An advective atmospheric mixed-layer model for ocean modeling purposesglobal simulation of surface heat fluxes. J. Climate, 8, 19511964.

Smith, S. D., and F. W. Dobson, 1984: The heat budget at Ocean Weather Station Bravo. Atmos.-Ocean, 22, 1-22.

Speer, K., and E. Tziperman, 1992: Rates of water mass formation in the North Atlantic Ocean. J. Phys. Oceanogr., 22, 93-104.

_- H.-J. Isemer, and A. Biastoch, 1995: Water mass formation from revised COADS data. J. Phys. Oceanogr., 25, 2444-2457.

Swift, J. H., 1984: The circulation of the Denmark Strait and IcelandScotland overflow waters in the North Atlantic. Deep-Sea Res., 31, 1339-1355.

K. Aagaard, and S.-A. Malmberg, 1980: The contribution of the Denmark Strait overflow to the deep North Atlantic. DeepSea Res. 27, 29-42.

Talley, L. D., and M. S. McCartney, 1982: Distribution and circulation 
of Labrador Sea Water. J. Phys. Oceanogr., 12, 1189-1205.

Top, Z., W. B. Clarke, W. C. Eismont, and E. P. Jones, 1981: Radiogenic helium in Baffin Bay bottom water. J. Mar. Res., 38, 435452.

Tziperman, E., 1986: On the role of interior mixing and air-sea fluxes in determining the stratification and circulation of the oceans. $J$. Phys. Oceanogr., 16, 680-693.

Unterweger, M. P., B. M. Coursey, F. J. Schima, and W. B. Mann, 1980: Preparation and calibration of the 1978 National Bureau of Standards tritiated-water standards. Int. J. Appl. Radiat. Isot., 31, 611-614.

Visbeck, M., J. Marshall, T. Haine, and M. Spall, 1997: Specification of eddy transfer coefficients in coarse-resolution ocean circulation models. J. Phys. Oceanogr., 27, 381-402.

Walin, G., 1982: On the relation between sea-surface heat flow and thermal circulation in the ocean. Tellus, 34, 187-195.

Wanninkhof, R., 1992: Relationship between wind speed and gas exchange over the ocean. J. Geophys. Res., 97, 7373-7382. 